\title{
When Does the Rate-Determining Step in the Hepatic Clearance of a Drug Switch from Sinusoidal Uptake to All Hepatobiliary Clearances? Implications for Predicting Drug-Drug Interactions ${ }^{\text {( }}$
}

\author{
D Gabriela I. Patilea-Vrana and Jashvant D. Unadkat \\ Department of Pharmaceutics, University of Washington, Seattle, Washington
}

Received March 7, 2018; accepted August 10, 2018

\section{ABSTRACT}

For dual transporter-enzyme substrate drugs, the extended clearance model can be used to predict the rate-determining step(s) (RDS) of a drug and hence predict its drug-drug interaction (DDI) liabilities (i.e., transport, metabolism, or both). If the RDS of the hepatic clearance of the drug is sinusoidal uptake clearance $\left(\mathrm{CL}_{\text {in }}^{\mathrm{s}}\right)$, even if the drug is eliminated mainly by hepatic metabolism, its DDI liability (as viewed from changes to systemic drug concentrations) is expected to be inhibition or induction of uptake transporters but not hepatic enzymes; however, this is true only if the condition required to maintain $\mathrm{CL}_{\text {in }}^{\mathrm{s}}$ as the RDS is maintained. Here, we illustrate through theoretical simulations that the RDS condition may be violated in the presence of a DDI. That is, the RDS of a drug can switch from $C_{\text {in }}^{s}$ to all hepatobiliary clearances [i.e., metabolic/biliary clearance $\left(\mathrm{CL}_{\text {met }}+\right.$ bile $)$ and $\mathrm{CL}_{\text {in }}^{\mathrm{s}}$ ], leading to unexpected systemic DDIs, such as metabolic DDIs, when only transporter DDIs were anticipated. As expected, these analyses revealed that the RDS switch depends on the ratio of $\mathrm{CL}_{\text {met }}+$ bile to sinusoidal efflux clearance ( $\left.C L_{\text {ef }}^{s}\right)$. Additional analyses revealed that for intravenously administered drugs, the RDS switch also depends on the magnitude of $\mathrm{CL}_{\mathrm{in}}^{\mathrm{s}}$. We analyzed published in vitro quantified hepatobiliary clearances and observed that most drugs have a $\mathrm{CL}_{\text {met + bile }} / \mathrm{CL}_{\text {ef }}^{\text {s }}$ ratio < 4; hence, in practice, the magnitude of $\mathrm{CL}_{\text {in }}^{\mathrm{s}}$ must be considered when establishing the RDS. These analyses provide insights previously not appreciated and a theoretical framework to predict DDI liabilities for drugs that are dual transporter-enzyme substrates.

\section{Introduction}

Identifying liabilities with respect to drug-drug interactions (DDI) is important in drug development. In 2015, 25 of the 33 new drug applications contained in vitro transporter data, and of 20 clinical trials using the new molecular entities (NMEs) as victim drugs, only nine resulted in a significant area under the curve (AUC) change (Yu et al., 2017). These data acknowledge that drug transporters are important in determining drug disposition (Giacomini et al., 2010; Hillgren et al., 2013; Patel et al., 2016).

As shown by the hepatic extended clearance model (ECM), when a drug is both transported into and metabolized or biliary-excreted by the liver, the rate-determining step (RDS) in the systemic clearance of the drug can be its hepatic uptake clearance, metabolic clearance, biliary (canalicular efflux) clearance, or all hepatobiliary clearances (Miyauchi et al., 1987; Sirianni and Pang, 1997; Shitara et al., 2006; Kusuhara and Sugiyama, 2009; Li et al., 2014; Patilea-Vrana and Unadkat, 2016). The RDS of a drug can be identified using models such as the Extended Clearance Concept Classification System and the Extended Clearance Classification System, which use the drug's in vitro quantified hepatobiliary clearance values or the drug's physicochemical properties,

This research was supported in part by National Institutes of Health National Institute of Drug Abuse [Grant P01DA032507].

https://doi.org/10.1124/dmd.118.081307.

S This article has supplemental material available at dmd.aspetjournals.org. respectively (Camenisch and Umehara, 2012; Varma et al., 2015). Using such models is advantageous since the RDS of a drug helps identify where the DDI liabilities lie. Of note, unless indicated otherwise, all subsequent references to DDI should be interpreted as those DDIs that can be observed from measurement of the systemic concentrations of the victim drug. For example, if the RDS of a drug is its hepatic uptake clearance $\left(\mathrm{RDS}_{\text {uptake}}\right)$, then the focus of the DDI studies should be transporter-based [e.g., hepatic organic anion-transporting polypeptide (OATP)-mediated uptake of atorvastatin] (Maeda et al., 2011) or if the RDS is both hepatic uptake and metabolic or biliary clearance ( $\operatorname{RDS}_{\text {all }}$ ), the focus of DDI studies should be all hepatobiliary pathways (e.g., OATP and cytochrome P450-mediated clearance of cerivastatin) (Mück et al., 1999; Backman et al., 2002).

Here, we asked whether knowledge of the RDS of a drug is enough to predict DDI liabilities for drugs that are dual transporter-enzyme substrates. If not, the focus of DDI studies will be misdirected and will result in either a negative or unexpected DDI and therefore toxicity. Under the worst-case scenario, the latter will lead to discontinuation of drug development and the end result is that both outcomes will increase drug development cost (Paul et al., 2010). For these reasons, it is important to ask whether the RDS can switch from hepatic uptake clearance to all hepatobiliary clearance pathways thus resulting in unexpected systemic DDIs. Using the ECM theory and simulations, we aimed to: 1) provide a theoretical framework of when the $\operatorname{RDS}_{\text {uptake }}$ switches to $\mathrm{RDS}_{\text {all }}$ in the presence of a DDI and 2) apply the RDS

ABBREVIATIONS: AUC, area under the curve; $\mathrm{AUCR}$, area under the curve ratio; $\mathrm{CL}_{\text {bile, }}$ biliary (canalicular) efflux clearance; $\mathrm{CL}_{\text {int }}$, intrinsic clearance; $\mathrm{CL}_{\text {met }}$, metabolic clearance; $C L_{\text {in }}^{\mathrm{s}}$, sinusoidal influx clearance; $\mathrm{CL}_{\mathrm{ef}}^{\mathrm{s}}$, sinusoidal efflux clearance; $\mathrm{DDI}$, drug-drug interaction; $\mathrm{ECM}$, extended clearance model; IVIVE, in vitro to in vivo extrapolation; NME, new molecular entity; OATP, organic anion transporting polypeptide; PBPK, physiologically based pharmacokinetics; $\mathrm{PI}_{\text {met }}+$ bile, percent inhibition of $\mathrm{CL}_{\text {met }}+$ bile necessary for $\mathrm{RDS}$ uptake to switch to RDS ${ }_{\text {all }}$; RDS, ratedetermining step. 
framework to predict DDI liabilities through theoretical and practical examples. The resulting analyses and simulations provide novel insights, hitherto not appreciated, into factors that determine when a victim drug experiences the $\mathrm{RDS}_{\text {uptake }}$ switch to $\mathrm{RDS}_{\text {all }}$ and elucidate important considerations for predicting DDI liabilities for drugs that are substrates of both hepatic transporters and enzymes.

\section{Materials and Methods}

Theoretical Background. The ECM describes complex hepatobiliary clearance in terms of transport at the sinusoidal membrane via sinusoidal influx $\left(\mathrm{CL}_{\text {in }}^{\mathrm{s}}\right)$ and efflux $\left(\mathrm{CL}_{\mathrm{ef}}^{\mathrm{s}}\right)$, transport at the canalicular membrane via biliary efflux $\left(\mathrm{CL}_{\text {bile }}\right)$, metabolism $\left(\mathrm{CL}_{\text {met }}\right)$, hepatic blood flow $\left(\mathrm{Q}_{\mathrm{h}}\right)$, and fraction unbound in blood ( $\left(\mathrm{fu}_{\mathrm{b}}\right.$ ) (eq. 1). $\mathrm{CL}_{\mathrm{in}}^{\mathrm{s}}$ and $\mathrm{CL}_{\mathrm{ef}}^{\mathrm{s}}$ terms incorporate both transport-mediated plus passive diffusion clearance, whereas $\mathrm{CL}_{\mathrm{b} \text { ile }}$ describes active transport only. The interrelationships between the hepatobiliary clearances defined by the ECM create the RDS in the hepatic clearance of a drug. As described by us and others (Miyauchi et al., 1987; Sirianni and Pang, 1997; Shitara et al., 2006; Patilea-Vrana

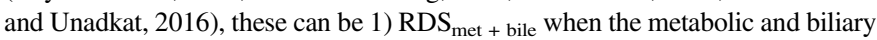
efflux clearances of the drug are much less than sinusoidal efflux clearance $\left(\mathrm{CL}_{\mathrm{met}}\right.$ + bile $<<\mathrm{CL}_{\mathrm{ef}}^{\mathrm{s}}$ ) and the drug is highly permeable (passive diffusion $>>$ active transport, $\mathrm{CL}_{\mathrm{in}}^{\mathrm{s}} \approx \mathrm{CL}_{\mathrm{ef}}^{\mathrm{s}}$ ) and thus can rapidly distribute across the sinusoidal membrane; 2) $\operatorname{RDS}_{\text {uptake }}$ when the metabolic plus biliary efflux clearances are much greater than the sinusoidal efflux clearance $\left(\mathrm{CL}_{\text {met }}+\right.$ bile $\left.>>\mathrm{CL}_{\mathrm{ef}}^{\mathrm{s}}\right)$, or 3 ) RDS $_{\text {all }}$ when a drug has both active transport and metabolism, but the preceding two extreme scenarios do not apply $\left(\mathrm{CL}_{\text {in }}^{\mathrm{s}} \neq \mathrm{CL}_{\text {ef }}^{\mathrm{s}}\right)$ :

$$
\mathrm{CL}_{\mathrm{h}}=\frac{\mathrm{Q}_{\mathrm{h}} \mathrm{fu}_{\mathrm{b}} \mathrm{CL}_{\text {in }}^{\mathrm{s}}\left(\mathrm{CL}_{\text {met }}+\mathrm{CL}_{\text {bile }}\right)}{\mathrm{Q}_{\mathrm{h}}\left(\mathrm{CL}_{\mathrm{ef}}^{\mathrm{s}}+\mathrm{CL}_{\text {met }}+\mathrm{CL}_{\text {bile }}\right)+\mathrm{fu}_{\mathrm{b}} \mathrm{CL}_{\text {in }}^{\mathrm{s}}\left(\mathrm{CL}_{\text {met }}+\mathrm{CL}_{\text {bile }}\right)} .
$$

Identifying the RDS of a drug can be used to predict the liability of transporter versus metabolic DDIs (see Patilea-Vrana and Unadkat, 2016, for simulations of systemic and hepatic AUC when hepatobiliary clearances are inhibited). For

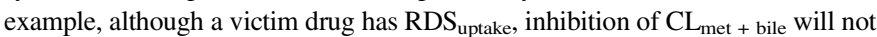
result in a significant increase in the systemic AUC, even though such DDI could result in significant drug accumulation in the liver and hence potentially enhance the hepatic efficacy or toxicity of the drug. That is, from the point of view of systemic (e.g., victim plasma concentrations) measurements, inhibition of $\mathrm{CL}_{\text {met }}+$ bile will be incorrectly interpreted as negative because there will be no change in systemic concentrations of the drug. On the other hand, inhibition of $\mathrm{CL}_{\text {in }}^{\mathrm{s}}$ will result in an increase in the drug's systemic AUC (and therefore potentially nonhepatic efficacy and toxicity of the drug) but will result in no changes in the hepatic AUC, provided the liver is the primary eliminating organ (for examples, see Patilea-Vrana and Unadkat, 2016). Less appreciated, however, is the fact that in the presence of metabolic or biliary efflux DDI, the RDS of a drug can switch from $\mathrm{RDS}_{\text {uptake }}$ to $\mathrm{RDS}_{\text {all }}$ and hence switch the DDI liability from uptake transporters to both metabolic or biliary and uptake pathways. Consequently, the drug's systemic AUC will significantly change owing to metabolic and biliary efflux DDIs, even though uptake was the RDS of the drug in the absence of a DDI, which would lead to unexpected DDIs as viewed from the systemic concentrations of the victim drug. Therefore, through MATLAB simulations (R2016a; MathWorks, Natick, MA), we illustrated when the RDS $_{\text {uptake-to-RDS }}$ all switch occurs for a victim drug in the presence of a DDI. We then applied our proposed RDS framework to published in vitro hepatobiliary clearances to determine whether in vivo observed DDI liabilities can be correctly predicted. Although the insights illustrated can be derived from analytical solutions of the ECM equation (eq. 1), for clarity, we chose to use simulations to illustrate the principles of these DDI liabilities within the RDS framework.

Simulation Assumptions. The hepatic ECM was simulated using the governing differential equations as previously described (Endres et al., 2009; Patilea-Vrana and Unadkat, 2016), and for simplicity, the following assumptions about the victim drug were made: 1) it was administered intravenously; 2) the fraction unbound (fu) in blood and tissue (liver) was set to 1;3) liver was the only eliminating organ; 4) $\mathrm{Q}_{\mathrm{h}}$ was set to 1 liter/min. All references to systemic AUC are derived from drug concentrations in blood. Our conclusions regarding the RDS switch are generalizable to when victim drugs are administered orally, but our conclusions of the RDS dependence on $\mathrm{CL}_{\text {in }}^{\mathrm{s}}$ apply only to intravenously administered drugs (see text to follow). Furthermore, for oral drug administration, our findings apply only to changes to the hepatic clearance and bioavailability of the victim drug and do not address the intestinal availability of the victim drug. If there is significant nonhepatic clearance, our conclusions will stand except that the magnitude of the change observed in the systemic and/or hepatic AUC of the drug will differ (Patilea-Vrana and Unadkat, 2016).

Identifying When the RDS uptake $_{\text {Switches to }} \mathbf{R D S}_{\text {all }}$ and Factors that Influence this Switch. First, we determined when the RDS of a drug switches from uptake clearance to all hepatobiliary clearance pathways. This requires violating the condition $\mathrm{CL}_{\mathrm{met}}+$ bile $>>\mathrm{CL}_{\mathrm{ef}}^{\mathrm{s}}$, the condition necessary for uptake clearance to be the RDS in the hepatic clearance of drug. To illustrate this effect, for three theoretical victim drugs, where $\mathrm{CL}_{\mathrm{met}}+$ bile $>>\mathrm{CL}_{\mathrm{ef}}^{\mathrm{s}}\left(\mathrm{CL}_{\mathrm{met}}+\right.$ bile $=1,10$, 100 liters $/ \mathrm{min}, \mathrm{CL}_{\mathrm{ef}}^{\mathrm{s}}=0.1 \mathrm{liter} / \mathrm{min}$, and $\mathrm{CL}_{\mathrm{in}}^{\mathrm{s}}=1 \mathrm{Q}_{\mathrm{h}}$ ), the systemic AUC ratio (AUCR) of the victim drug in the absence and presence of 10\%-99\% inhibition of $\mathrm{CL}_{\text {met }}+$ bile was simulated. In accordance with Food and Drug Administration guidelines, an AUCR of 1.25 was considered significant.

To illustrate that the $\mathrm{CL}_{\text {met }}+$ bile $/ \mathrm{CL}_{\mathrm{ef}}^{\mathrm{s}}$ ratio, and not the absolute magnitude of $\mathrm{CL}_{\text {met }}+$ bile and/or $\mathrm{CL}_{\mathrm{ef}}^{\mathrm{s}}$, determines when the $\mathrm{RDS}_{\text {uptake }}$ switches to $\mathrm{RDS}_{\text {all }}$, we conducted the following simulations: the systemic AUC of the drug was simulated for $\mathrm{CL}_{\mathrm{ef}}^{\mathrm{s}}$ values ranging from 0.1 to 10 liters/min (representing $0.1 \times$ to $10 \times \mathrm{Q}_{\mathrm{h}}$ ) with $\mathrm{CL}_{\text {met }}+$ bile set to 1 - to 20 -fold the value of the corresponding $\mathrm{CL}_{\text {ef. }}^{\mathrm{s}}$. The simulated systemic AUCs, when the $\mathrm{CL}_{\text {met }+ \text { bile }} / \mathrm{CL}_{\mathrm{ef}}^{\mathrm{s}}$ ratio was held constant, were compared with the simulated systemic AUCs when $\mathrm{CL}_{\text {met }}+$ bile $/ \mathrm{CL}_{\mathrm{ef}}^{\mathrm{s}}$ ratio varied.

Next, we defined the tipping point as the $\mathrm{CL}_{\text {met }+ \text { bile }} / \mathrm{CL}_{\mathrm{ef}}^{\mathrm{s}}$ ratio, at which $\mathrm{RDS}_{\text {uptake }}$ switches to $\mathrm{RDS}_{\text {all }}$. Following the same strategy, we simulated the AUCR for various $\mathrm{CL}_{\text {met }}+$ bile $/ \mathrm{CL}_{\mathrm{ef}}^{\mathrm{s}}$ ratios for victim drugs that originally had $\mathrm{RDS}_{\text {uptake }}$ to illustrate the $\mathrm{CL}_{\text {met }+ \text { bile }} / \mathrm{CL}_{\mathrm{ef}}^{\mathrm{s}}$ ratio at which AUCR $=1.25$, thus signifying that $\mathrm{RDS}_{\text {uptake }}$ switched to $\mathrm{RDS}_{\text {all }}$. The systemic AUC where the RDS is uptake was simulated such that the

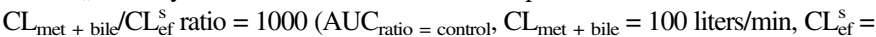
$0.1 \mathrm{liter} / \mathrm{min}$ ). Then, systemic AUC was simulated for $\mathrm{CL}_{\text {met }+ \text { bile }} / \mathrm{CL}_{\mathrm{ef}}^{\mathrm{s}}$ "test" ratios ranging from 0.1 to $10\left(\mathrm{CL}_{\text {met }}+\right.$ bile $\left.=0.01-1 \mathrm{liter} / \mathrm{min}, \mathrm{CL}_{\mathrm{ef}}^{\mathrm{s}}=0.1 \mathrm{liters} / \mathrm{min}\right)$, and the resulting $\mathrm{AUC}\left(\mathrm{AUC}_{\text {ratio }}=\right.$ test $)$ was normalized to the control simulation $(\mathrm{AUCR}=$ $\mathrm{AUC}_{\text {ratio }}=$ test $/ \mathrm{AUC}_{\text {ratio }}=$ control $)$. The decrease in $\mathrm{CL}_{\text {met }}+$ bile $/ \mathrm{CL}_{\text {ef }}^{\mathrm{s}}$ ratio is akin to inhibition of $\mathrm{CL}_{\text {met + bile }}$ since $\mathrm{CL}_{\mathrm{ef}}^{\mathrm{s}}$ is held constant. The $\mathrm{CL}_{\mathrm{met}}+$ bile $/ \mathrm{CL}_{\mathrm{ef}}^{\mathrm{s}}$ ratio, which resulted in a significant change to the systemic AUC (AUCR =1.25) compared with control, was identified as the tipping point.

To illustrate that the magnitude of $\mathrm{CL}_{\mathrm{in}}^{\mathrm{s}}$ contributes to the tipping point, we simulated the tipping point for $\mathrm{CL}_{\mathrm{in}}^{\mathrm{s}}$ values ranging from $0.01 \times \mathrm{Q}_{\mathrm{h}}$ to $4 \times \mathrm{Q}_{\mathrm{h}}$ (henceforth, for simplicity, $\mathrm{CL}_{\mathrm{in}}^{\mathrm{s}}$ notation will be used instead of $\mathrm{fu}_{\mathrm{b}} \mathrm{CL}_{\mathrm{in}}^{\mathrm{s}}$ since $\mathrm{fu}_{\mathrm{b}}=1$ ). The tipping point can be explicitly derived from the ECM (eq. 1) by defining the RDS switch for any chosen AUCR as AUCR $=\mathrm{RDS}_{\text {uptake }} / \mathrm{RDS}_{\text {all }}$ and solving for the $\mathrm{CL}_{\text {met }}+$ bile $/ C L_{\mathrm{ef}}^{\mathrm{s}}$ ratio (eq. 2). This relationship (eq. 2 with AUCR $=1.25$ ) was used later to identify DDI liabilities when considering $C_{\text {in }}^{\mathrm{s}}$ magnitude and $\mathrm{CL}_{\mathrm{met}}+$ bile $/ \mathrm{CL}_{\mathrm{ef}}^{\mathrm{s}}$ ratio of a drug:

$$
\text { Tippingpoint }=\frac{1}{(A U C R-1)\left(1+C L_{\text {in }}^{s} / Q_{h}\right)}
$$

Quantifying When a Drug with RDS $_{\text {uptake }}$ Will Switch to RDS $_{\text {all }}$ from Metabolic/Biliary Efflux DDIs. We defined the $\underline{\mathrm{PI}}_{\mathrm{met}}+$ bile as the percent inhibition of $\mathrm{CL}_{\text {met }}+$ bile required for $\mathrm{RDS}_{\text {uptake }}$ to switch to $\mathrm{RDS}_{\text {all }}$. This quantifies when a significant DDI (AUCR $\geq 1.25$ ) occurs from inhibition of $\mathrm{CL}_{\text {met }}+$ bile, even when uptake is the RDS in the absence of DDI. For $\mathrm{CL}_{\text {met }+ \text { bile }} / \mathrm{CL}_{\mathrm{ef}}^{\mathrm{s}}$ ratios ranging from 1 to $100, \mathrm{CL}_{\text {met }}+$ bile was inhibited $10 \%-99 \%$. Simulations were conducted for $\mathrm{CL}_{\mathrm{in}}^{\mathrm{s}}$ values $=0.25,1 \times, 4 \times \mathrm{Q}_{\mathrm{h}} \cdot \mathrm{CL}_{\mathrm{in}}^{\mathrm{s}}$ values were chosen to represent $\mathrm{ER}=0.2,0.5$, and 0.8 [low-, mid-, and high-extraction ratio (ER), respectively] and were back-calculated from eq. 3 to eq. 4 . The percent inhibition of $\mathrm{CL}_{\text {met + bile }}$ at which the $\mathrm{CL}_{\text {met + bile }} / \mathrm{CL}_{\mathrm{ef}}^{\mathrm{s}}$ ratio reaches the tipping point (i.e., $\mathrm{PI}_{\text {met }}+$ bile) and thus causes the $\mathrm{RDS}_{\text {uptake }}$ to switch to $\mathrm{RDS}_{\text {all }}$ was calculated as shown in eq. 5 :

$$
\begin{gathered}
\mathrm{CL}_{\mathrm{h}}=\mathrm{Q}_{\mathrm{h}}{ }^{* E R} \\
\mathrm{CL}_{\mathrm{h}}=\frac{\mathrm{Q}_{\mathrm{h}} \mathrm{fu}_{\mathrm{b}} \mathrm{CL}_{\text {in }}^{\mathrm{s}}}{\mathrm{Q}_{\mathrm{h}}+\mathrm{fu}_{\mathrm{b}} \mathrm{CL}_{\text {in }}^{\mathrm{s}}} \\
\mathrm{PI}_{\text {met }+ \text { bile }}(\%)=\frac{\mathrm{CL}_{\text {met }+ \text { bile }} / \mathrm{CL}_{\mathrm{ef}}^{\mathrm{s}}-\text { tippingpoint }}{\mathrm{CL}_{\text {met }+ \text { bile }} / \mathrm{CL}_{\mathrm{ef}}^{\mathrm{s}}} \times 100
\end{gathered}
$$


Applying the RDS Framework to In Vitro and In Vivo Examples. Published data sets in which all hepatobiliary clearance pathways $\left(\mathrm{CL}_{\mathrm{in}}^{\mathrm{s}}, \mathrm{CL}_{\mathrm{ef}}^{\mathrm{s}}\right.$, $\mathrm{CL}_{\text {bile }}, \mathrm{CL}_{\text {met }}$ ) were quantified in vitro were collected. The in vivo hepatobiliary clearances must be used to identify the RDS of a drug. As such, the provided in vitro to in vivo extrapolated (IVIVE) clearances were used; otherwise, in vitro hepatobiliary clearance values were scaled to in vivo using IVIVE scaling factors as provided by the authors. For all drugs, $\mathrm{fu}_{\mathrm{b}} \mathrm{CL}_{\mathrm{in}}^{\mathrm{s}} / \mathrm{Q}_{\mathrm{h}}$ was used to calculate the tipping point using eq. 2 (see Results section to follow). RDS was labeled as $\mathrm{RDS}_{\text {uptake }}$ and RDS all if the $\mathrm{CL}_{\text {met + bile }} / \mathrm{CL}_{\mathrm{ef}}^{\mathrm{S}}$ ratio was above and below the tipping point, respectively. For drugs with $\operatorname{RDS}_{\text {uptake }}$, the $\mathrm{PI}_{\text {met }}+$ bile was calculated using eq. 5. Finally, for selected drugs, the predicted DDI liabilities using the RDS and $\mathrm{PI}_{\text {met }+ \text { bile }}$ were compared with the observed in vivo data. To ensure that only the systemic clearance, and not the bioavailability of the victim drug, was affected, clinical DDI studies were included if the victim was a dual- transporter/enzyme substrate and coadministered with a selective enzyme inhibitor administered i.v. It should be noted that the availability of such studies was limited.

\section{Results}

Identifying the Tipping Point (i.e., When RDS uptake $_{\text {Switches to }}$ RDS $_{\text {all }}$ ) and Factors that Influence this Switch. As described in the Theoretical Background section, $\operatorname{RDS}_{\text {uptake }}$ occurs when $\mathrm{CL}_{\text {met + bile }}>>$
$\mathrm{CL}_{\mathrm{cf}}$, and, as such, inhibition of $\mathrm{CL}_{\mathrm{met}}+$ bile will not manifest in the systemic AUC of a victim drug. When this condition is violated owing to extensive inhibition of $\mathrm{CL}_{\text {met }}+$ bile, there will be a significant increase in the systemic AUC of the victim drug when $\mathrm{CL}_{\text {met }}+$ bile is inhibited further. In other words, when $\mathrm{CL}_{\text {met }}+$ bile is no longer $>>\mathrm{CL}_{\mathrm{ef}}^{\mathrm{s}}$, then $\mathrm{RDS}_{\text {uptake }}$ switches to $\mathrm{RDS}_{\text {all }}$. In Fig. $1 \mathrm{~A}, 84 \%, 98 \%$, and $99.8 \%$ inhibition of $\mathrm{CL}_{\text {met }}+$ bile led to a clinically significant increase in the systemic AUC of the three theoretical victim drugs shown (AUCR $\geq$ 1.25). Even though the victim drugs had different preinhibition $C_{\text {met }}+$ bile values $\left(1,10,100\right.$ liters/min), the postinhibition $\mathrm{CL}_{\text {met }}+$ bile values were all the same $\left(0.2\right.$ liters/min). Since $\mathrm{CL}_{\mathrm{ef}}^{\mathrm{s}}$ was kept constant $(0.1$ liters/min), an AUCR of 1.25 was observed when $\mathrm{CL}_{\mathrm{met}}+$ bile $/ \mathrm{CL}_{\mathrm{ef}}^{\mathrm{s}}=$ 2 for all three victim drugs. This simulation illustrates that the RDS $_{\text {uptake }}$ switch to $\mathrm{RDS}_{\text {all }}$ depends on the $\mathrm{CL}_{\text {met }+ \text { bile }} / \mathrm{CL}_{\mathrm{ef}}^{\mathrm{s}}$ ratio, not on the extent of $\mathrm{CL}_{\text {met + bile }}$ inhibition.

To further emphasize the dependence on the $\mathrm{CL}_{\text {met }+ \text { bile }} / \mathrm{CL}_{\mathrm{ef}}^{\mathrm{s}}$ ratio, we simulated the systemic AUC of the victim drug (in the absence of DDI) for different $\mathrm{CL}_{\mathrm{met}}+$ bile and $\mathrm{CL}_{\mathrm{ef}}^{\mathrm{s}}$ values while holding $\mathrm{CL}_{\mathrm{in}}^{\mathrm{s}}$ constant. The systemic AUC remained unchanged when the $\mathrm{CL}_{\text {met }+ \text { bile }} / \mathrm{CL}_{\mathrm{ef}}^{\mathrm{s}}$ ratio remained fixed, even though the $\mathrm{CL}_{\mathrm{met}}+$ bile and $\mathrm{CL}_{\mathrm{ef}}^{\mathrm{s}}$ values varied,
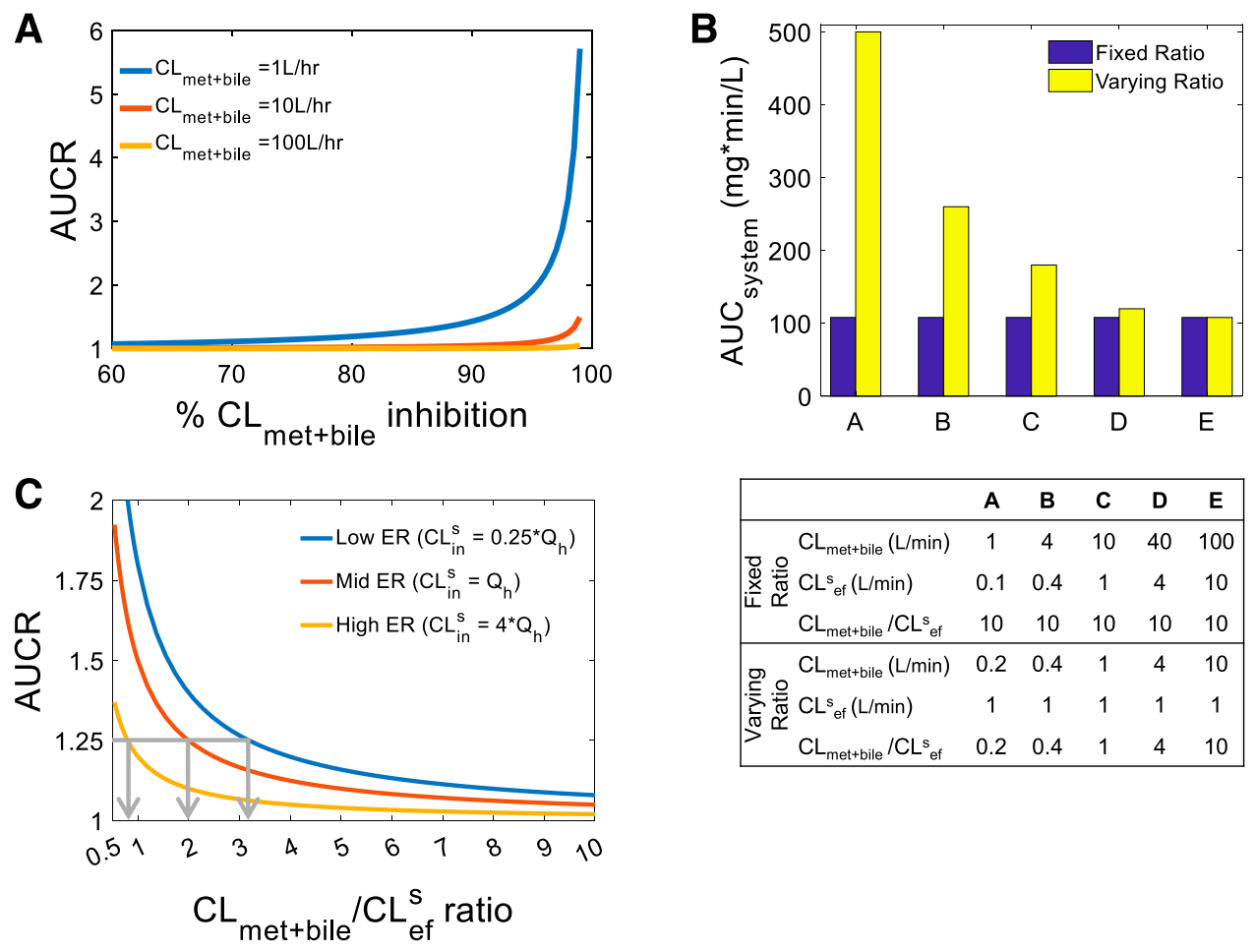

\begin{tabular}{|c|c|c|c|c|c|c|}
\hline & & $\mathbf{A}$ & B & C & D & $E$ \\
\hline \multirow{3}{*}{ 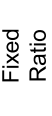 } & $\mathrm{CL}_{\text {met+bile }}(\mathrm{L} / \mathrm{min})$ & 1 & 4 & 10 & 40 & 100 \\
\hline & $\mathrm{CL}_{\mathrm{ef}}(\mathrm{L} / \mathrm{min})$ & 0.1 & 0.4 & 1 & 4 & 10 \\
\hline & $C L_{\text {met+bile }} / C L_{\text {ef }}^{\text {s }}$ & 10 & 10 & 10 & 10 & 10 \\
\hline \multirow{3}{*}{ 离。 } & $\mathrm{CL}_{\text {met+bile }}(\mathrm{L} / \mathrm{min})$ & 0.2 & 0.4 & 1 & 4 & 10 \\
\hline & $\mathrm{CL}_{\mathrm{ef}}^{\mathrm{s}}(\mathrm{L} / \mathrm{min})$ & 1 & 1 & 1 & 1 & 1 \\
\hline & $\mathrm{CL}_{\text {met+bile }} / \mathrm{CL}_{\text {ef }}$ & 0.2 & 0.4 & 1 & 4 & 10 \\
\hline
\end{tabular}

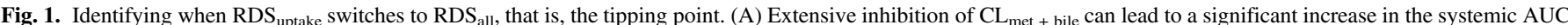

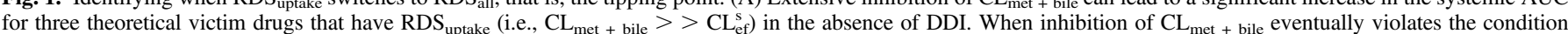

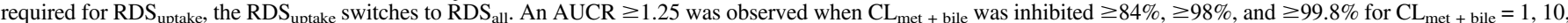

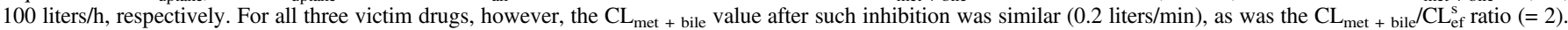

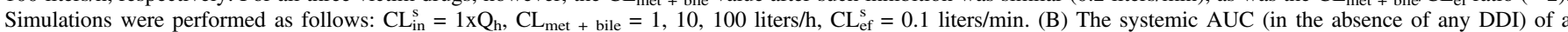

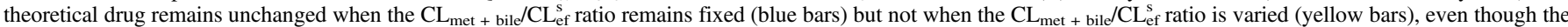

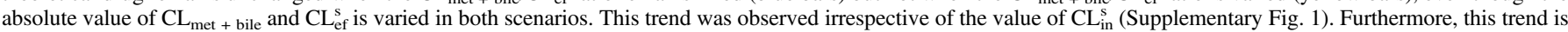

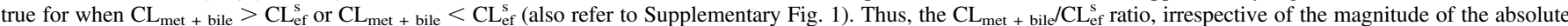

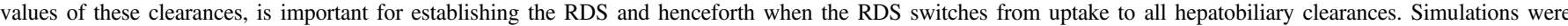

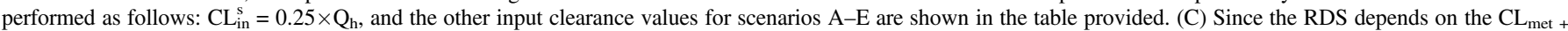

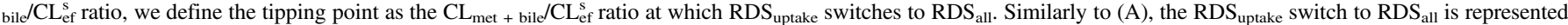

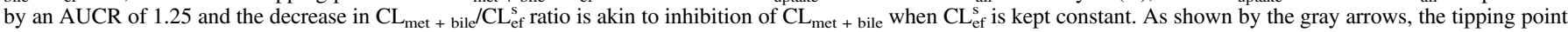

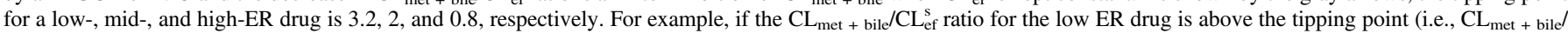

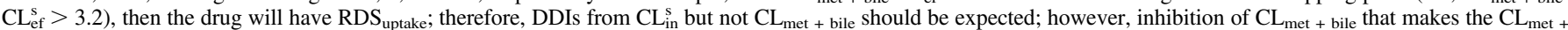

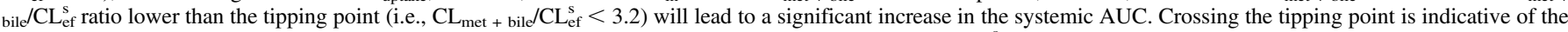

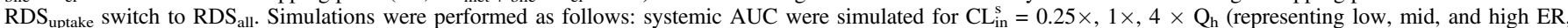
respectively) and $\mathrm{CL}_{\text {met }}+$ bile $/ \mathrm{CL}_{\mathrm{ef}}^{\mathrm{s}}$ ratios from 1 to 10 and then normalized to a control simulation where the $\mathrm{CL}_{\text {met }+ \text { bile }} / \mathrm{CL}_{\mathrm{ef}}^{\mathrm{s}}$ ratio was set to 1000 (i.e., $\mathrm{RDS}$ uptake). 
demonstrating that the RDS in the hepatic clearance of a drug is dependent on the $\mathrm{CL}_{\text {met }}+$ bile $/ \mathrm{CL}_{\mathrm{ef}}^{\mathrm{s}}$ ratio, not on the absolute value of these clearances (Fig. 1B). This was true for both when $\mathrm{CL}_{\text {met }}+$ bile was higher and lower than $\mathrm{CL}_{\mathrm{ef}}^{\mathrm{s}}$ (also see Supplementary Fig. 1). Since the systemic AUC decreased as the $\mathrm{CL}_{\text {met }}+$ bile $/ \mathrm{CL}_{\mathrm{ef}}^{\mathrm{s}}$ ratio increased, only the $\mathrm{CL}_{\text {met }}+$ bile $/ \mathrm{CL}_{\text {ef }}^{\mathrm{s}}$ ratio needs to be considered when determining when the $\operatorname{RDS}_{\text {uptake }}$ switches to $\operatorname{RDS}_{\text {all }}$ for a victim drug.

Next, we identified the tipping point, defined here as the $\mathrm{CL}_{\text {met }+ \text { bile }} / \mathrm{CL}_{\text {ef }}^{\mathrm{s}}$ ratio when $R_{\text {DS }}$ uptake switches to $R D S_{\text {all }}$. The $\operatorname{RDS}_{\text {uptake }}$ switch to $\operatorname{RDS}_{\text {all }}$ signifies when DDIs owing to inhibition of $\mathrm{CL}_{\text {met }}+$ bile start to become significant for a victim drug that has $\operatorname{RDS}_{\text {uptake }}$. As demonstrated already, the $\mathrm{RDS}_{\text {uptake }}$ switch to $\mathrm{RDS}_{\text {all }}$ depends on the $\mathrm{CL}_{\text {met }}+$ bile $/ \mathrm{CL}_{\mathrm{ef}}^{\mathrm{s}}$ ratio. As such, we identified the tipping point as the $\mathrm{CL}_{\text {met }+ \text { bile }} / \mathrm{CL}_{\mathrm{ef}}^{\mathrm{s}}$ ratio at which the systemic AUC increases significantly (AUCR = 1.25) owing to a decrease in the $\mathrm{CL}_{\text {met }}+$ bile $/ C L_{\mathrm{ef}}^{\mathrm{s}}$ ratio for a victim drug that has $\mathrm{RDS}_{\text {uptake }}$ (Fig. 1C). As demonstrated in Fig. 1C, the tipping point for a low, mid, and high ER drug was 3.2, 2, and 0.8, respectively.

Since the tipping point varied for a low, mid, and high ER, the magnitude of $\mathrm{CL}_{\mathrm{in}}^{\mathrm{s}}$ is also an important factor in determining when the $\mathrm{RDS}_{\text {uptake }}$ switches to $\mathrm{RDS}_{\text {all }}$ (Fig. 1C). Extending the simulations to identify the tipping point across a range of $\mathrm{CL}_{\text {in }}^{\mathrm{s}}$ values, we established a theoretical (eq. 2) and practical (Fig. 2) relationship between $\mathrm{CL}_{\mathrm{in}}^{\mathrm{s}} / \mathrm{Q}_{\mathrm{h}}$ and the tipping point. The tipping point decreases as $\mathrm{CL}_{\text {in }}^{\mathrm{s}}$ increases. In other words, as a drug's $\mathrm{CL}_{\mathrm{in}}^{\mathrm{s}}$ (and therefore its ER) increases, the drug is more likely to have $\mathrm{RDS}_{\text {uptake }}$ and a larger $\mathrm{PI}_{\text {met + bile, therefore making }}$ the drug more resistant to switching its RDS. In addition, as the influx across the sinusoidal membrane becomes large, hepatic clearance becomes limited by blood flow and therefore less likely to result in a change in AUCR when either $\mathrm{CL}_{\text {in }}^{\mathrm{s}}$ (or for that matter $\mathrm{CL}_{\text {met }}+$ bile) is inhibited. On the other hand, when $\mathrm{CL}_{\text {in }}^{\mathrm{s}}$ (or ER) is small and the hepatic clearance becomes proportional to $\mathrm{CL}_{\mathrm{in}}^{\mathrm{s}}$, the victim drug becomes more susceptible to a change in RDS. This demonstrates that low ER drugs are more susceptible to $\mathrm{RDS}_{\text {uptake }}$ switching to $\mathrm{RDS}_{\text {all }}$, whereas high ER drugs are more resistant to the RDS switch.

It should be noted that the relationship between $\mathrm{CL}_{\text {in }}^{\mathrm{s}} / \mathrm{Q}_{\mathrm{h}}$ and the tipping point (eq. 2 and Fig. 2) depends on the chosen AUCR cutoff. Here, an AUCR of 1.25 was chosen based on Food and Drug Administration guidelines of what constitutes a positive DDI. If a higher AUCR cutoff were to be selected (Supplementary Fig. 2), this would lead to estimation of lower tipping points, thus making it more likely that drugs are labeled with $\operatorname{RDS}_{\text {uptake }}$. Labeling a drug with RDS $_{\text {uptake }}$ when in fact it has $\mathrm{RDS}_{\text {all }}$ can lead to underpredictions of DDI liabilities from metabolic enzymes and biliary transporters.

By understanding the relationship between $\mathrm{CL}_{\text {in }}^{\mathrm{s}}$ and the tipping point, the RDS can be identified for any combination of a drug's hepatobiliary clearance values (Fig. 2). For example, a high-ER drug with a $\mathrm{CL}_{\text {met + bile }} / \mathrm{CL}_{\mathrm{ef}}^{\mathrm{s}}$ ratio of 3 will have $\mathrm{RDS}_{\text {uptake, }}$, but a low-ER drug with the same $\mathrm{CL}_{\text {met }}+$ bile $/ \mathrm{CL}_{\mathrm{ef}}^{\mathrm{s}}$ ratio will have $\mathrm{RDS}_{\text {all }}$. Furthermore, a drug will always have $\mathrm{RDS}_{\text {uptake }}$ if the $\mathrm{CL}_{\text {met }}+$ bile $/ \mathrm{CL}_{\mathrm{ef}}^{\mathrm{s}}$ ratio is greater than 4 , irrespective of the magnitude of $C L_{\text {in }}^{\mathrm{s}}$. It should be noted that for orally administered drugs, the tipping point will no longer depend on the magnitude of $\mathrm{CL}_{\text {in }}^{\mathrm{s}}$ and therefore will always be 4 because blood flow limitations from systemic clearance are cancelled out by blood flow limitations of hepatic bioavailability.

Quantifying the $\mathbf{P I}_{\text {met + bile }}$ for Drugs with $\mathbf{R D S}_{\text {uptake }}$ Identifying the RDS of a drug and when the RDS uptake $_{\text {to }}$ RDS $_{\text {all }}$ switch will happen identifies the drug's DDI liabilities. We quantified the $\mathrm{PI}_{\text {met }}+$ bile, defined here as the percent inhibition of $\mathrm{CL}_{\text {met }}+$ bile needed to cause the $\mathrm{RDS}_{\text {uptake }}$ switch to RDS all, to understand when inhibition of $\mathrm{CL}_{\text {met }}+$ bile starts to become a DDI liability for victim drugs that have $\operatorname{RDS}_{\text {uptake. As }}$ the $\mathrm{CL}_{\text {met }}+$ bile $/ \mathrm{CL}_{\mathrm{ef}}^{\mathrm{s}}$ ratio of the victim drug (before inhibition) increases, the $\mathrm{PI}_{\text {met }+ \text { bile }}$ increases (Fig. 3A) because, as $\mathrm{CL}_{\text {met }+ \text { bile }}$ becomes $>>$

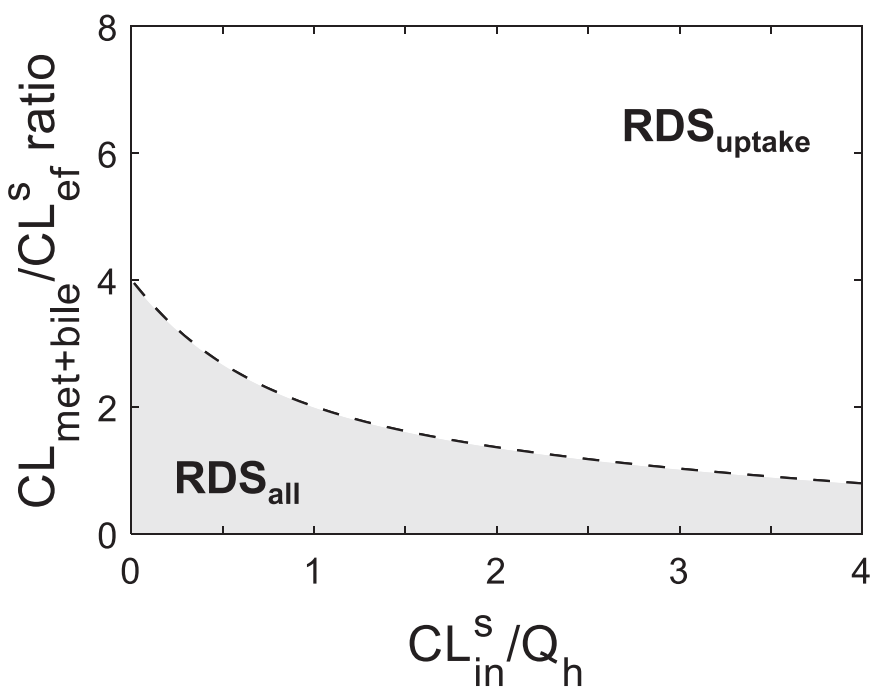

Fig. 2. The RDS framework helps identify DDI liabilities. The $\mathrm{CL}_{\mathrm{met}}+$ bile $/ \mathrm{CL}_{\mathrm{ef}}^{\mathrm{s}}$ ratio and $C L_{\text {in }}^{\mathrm{s}}$ magnitude of a drug determine the RDS of the drug and when $\operatorname{RDS}_{\text {uptake }}$ switches to $\mathrm{RDS}_{\text {all }}$. Combinations of hepatobiliary clearances found in the shaded area have RDS all, whereas those in the nonshaded area have $\operatorname{RDS}_{\text {uptake. Any alterations in hepatobiliary }}$ clearances that cause a drug to switch from the nonshaded to the shaded area will cross the tipping point (dashed line, eq. 2) and therefore switch the RDS from uptake to all hepatobiliary clearances. The consequence of this switch is that DDIs from inhibition of $\mathrm{CL}_{\text {met }}+$ bile will now manifest in the systemic AUC of a victim drug that originally had $\operatorname{RDS}_{\text {uptake. }}$ Consistent with Fig. $1 \mathrm{C}$, the tipping point decreases as the magnitude of $\mathrm{CL}_{\text {in }}^{\mathrm{s}}$ (and therefore the drug's ER) increases. This suggests that the greater the ER of the drug, the more likely it will have $\operatorname{RDS}_{\text {uptake }}$ and will be more resistant to switch to $\mathrm{RDS}_{\text {all }}$. Furthermore, when $\mathrm{CL}_{\text {met }}+{ }_{\text {bile }} / \mathrm{CL}_{\mathrm{ef}}^{\mathrm{s}}>4$, the RDS will always be uptake clearance, irrespective of the value of $\mathrm{CL}_{\mathrm{in}}^{\mathrm{s}} / \mathrm{Q}_{\mathrm{h}}$; however, when $\mathrm{CL}_{\mathrm{met}}+$ bile $/ \mathrm{CL}_{\mathrm{ef}}^{\mathrm{s}}<4$, the RDS can be either uptake or all hepatobiliary pathways, depending on the magnitude of $\mathrm{CL}_{\mathrm{in}}^{\mathrm{s}}$. It should be noted that if a drug is administered orally, the tipping point will always be 4 because the blood flow limitations are no longer relevant. Simulations were performed as follows: the tipping point was simulated for $\mathrm{CL}_{\text {in }}^{\mathrm{s}}$ values $\left(0.01 \times \mathrm{Q}_{\mathrm{h}}\right.$ $4 \times \mathrm{Q}_{\mathrm{h}}$ ) using eq. 2 .

than $\mathrm{CL}_{\mathrm{ef}}^{\mathrm{s}}$, the victim drug become resistant to the $\mathrm{RDS}_{\text {uptake }}$ switch to $\mathrm{RDS}_{\text {all }}$. High-ER drugs have a higher $\mathrm{PI}_{\text {met }}+$ bile than low-ER drugs, demonstrating again that high-ER drugs are resistant to the RDS switch, whereas low-ER drugs are sensitive (Fig. 3A). Figure 3B illustrates that whereas a low-, mid-, and high-ER victim drug with $\mathrm{CL}_{\text {met }}+$ bile $/ \mathrm{CL}_{\mathrm{ef}}^{\mathrm{s}}$ ratio of 6 have $\mathrm{RDS}_{\text {uptake }}$ (before inhibition), inhibition of $\mathrm{CL}_{\text {met }+ \text { bile }}>46 \%$, $66 \%$, and $87 \%$, respectively, will cause the $\operatorname{RDS}_{\text {upake }}$ to switch to $\operatorname{RDS}_{\text {all }}$. This translates to observing a positive DDI owing to inhibition of $\mathrm{CL}_{\text {met }}+$ bile for a victim drug that has been identified to have $\operatorname{RDS}_{\text {uptake }}$ (before inhibition).

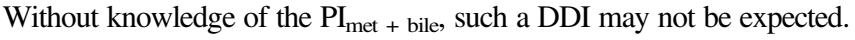

The purpose and conclusions of the simulations that have been used to establish the RDS framework up to this point are summarized in Fig. 4. As discussed, identifying the drug's RDS is not enough to predict correctly the drug's DDI liabilities. The tipping-point concept is an important consideration when identifying DDIs for victim drugs that are dual substrates of enzymes and transporters.

The flowchart in Fig. 5 can be used as a guide to identify the DDI liabilities for dual-transporter/enzyme substrates. All drugs with $\mathrm{CL}_{\text {met }}+$ bile $\mathrm{CL}_{\text {ef }}^{\mathrm{s}}$ ratio $>4$ will have $\mathrm{RDS}_{\text {uptake, }}$ whereas drugs with $\mathrm{CL}_{\text {met }+ \text { bile }} / \mathrm{CL}_{\mathrm{ef}}^{\mathrm{s}}$ ratio $<4$ will have $\operatorname{RDS}_{\text {uptake }}$ so long as this ratio is greater than the tipping point. Drugs with $\mathrm{CL}_{\text {met }}+$ bile $/ \mathrm{CL}_{\mathrm{ef}}^{\mathrm{s}}$ ratio less than the tipping point will have $\mathrm{RDS}_{\text {all }}$. If the drug has $\mathrm{RDS}_{\text {uptake, then uptake }}$ transporters will become a DDI liability, whereas if the drug has $\operatorname{RDS}_{\text {all }}$, then transporters and enzymes will be a DDI liability. Even for drugs that have $\mathrm{RDS}_{\text {uptake, }}$, however, $\mathrm{CL}_{\text {met }}+$ bile can become a DDI liability if inhibition of $\mathrm{CL}_{\text {met }}+$ bile is greater than the predicted $\mathrm{PI}_{\text {met }}+$ bile and thus causes the $\mathrm{RDS}_{\text {uptake }}$ switch to $\mathrm{RDS}_{\text {all }}$. The flowchart identifies the 
A

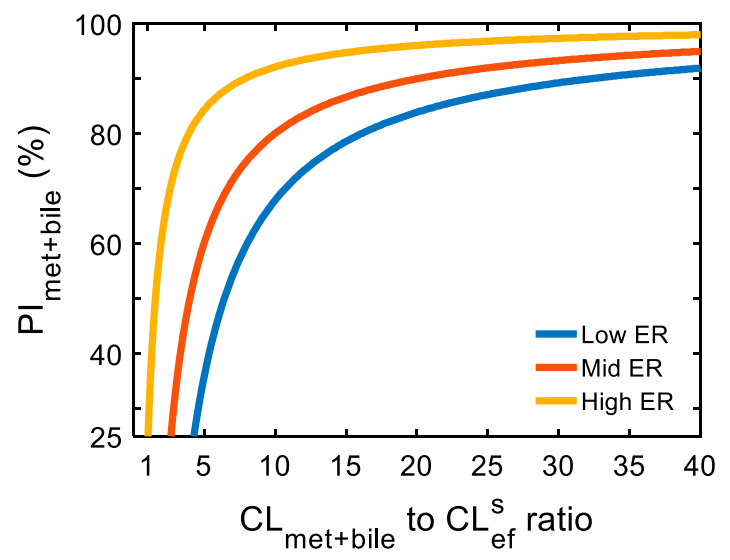

B

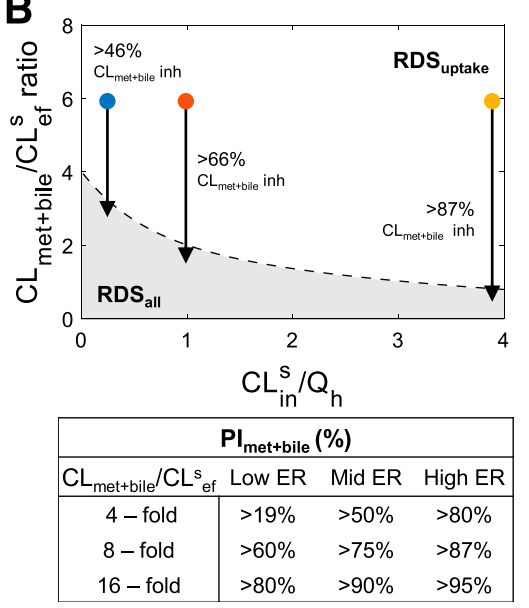

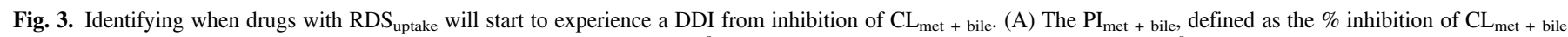

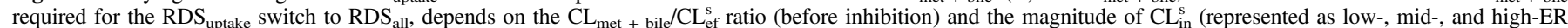

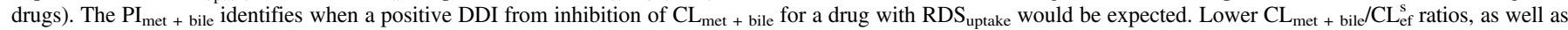

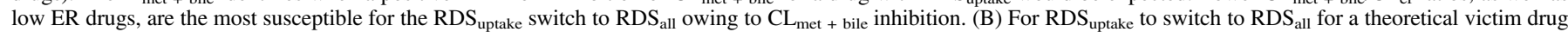

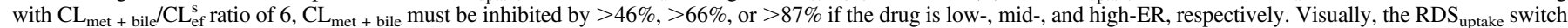

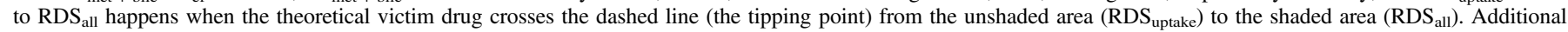

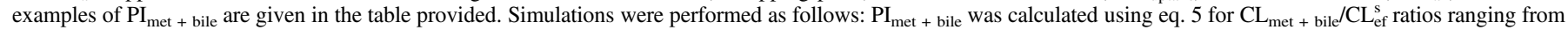
1 to 40 and for $\mathrm{CL}_{\mathrm{in}}^{\mathrm{s}}=0.25 \times, 1 \times, 4 \times \mathrm{Q}_{\mathrm{h}}$ (representing low-, mid-, and high-ER, respectively).

$\mathrm{CL}_{\text {met }}+$ bile $/ \mathrm{CL}_{\mathrm{ef}}^{\mathrm{s}}$ ratios at which $25 \%, 50 \%, 75 \%$, and $95 \%$ expected inhibition of $\mathrm{CL}_{\text {met }}+$ bile is going to result in the RDS switch. This information can be used to assess when $\mathrm{CL}_{\text {met }}+$ bile starts to become a

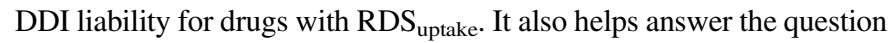
of how much larger $\mathrm{CL}_{\text {met }}+$ bile needs to be compared with $\mathrm{CL}_{\mathrm{ef}}^{\mathrm{s}}$ for sinusoidal uptake clearance to become (and maintain) the RDS in the hepatic clearance of any drug. Such information may be used during drug development to select drug candidates if a certain RDS is desired.

Applying the RDS Framework to In Vitro and In Vivo Examples. To provide context to the theoretical framework presented, examples from literature, where available, were used. For drugs with in vitro-quantified hepatobiliary clearances that were extrapolated to in vivo via IVIVE, the tipping point and the $\mathrm{PI}_{\text {met }+ \text { bile were calculated }}$ using eq. 2 and eq. 5 , and a subset of the analyzed data set, which includes primarily statin drugs, is shown in Fig. 6 (also see Supplementary Table 1) (Camenisch and Umehara, 2012; Jones et al., 2012; Varma et al., 2014; Kunze et al., 2015; Riede et al., 2017). If no empirical scaling factors (such as for active uptake clearance to match observed in vivo clearance) are included in the IVIVE process, then almost all drugs have $\mathrm{RDS}_{\mathrm{all}}$, except valsartan and pravastatin (Fig. 6A). This is because most $\mathrm{CL}_{\text {met }+ \text { bile }} / \mathrm{CL}_{\mathrm{ef}}^{\mathrm{s}}$ ratios are $<4$, and because the IVIVE $\mathrm{CL}_{\text {in }}^{\mathrm{s}}$ magnitudes were small, most $\mathrm{CL}_{\text {met }}+$ bile $/ \mathrm{CL}_{\mathrm{ef}}^{\mathrm{s}}$ ratios were less than the tipping point. Because many

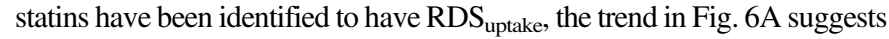
that $\mathrm{CL}_{\text {in }}^{\mathrm{S}}$ was underestimated in vitro. When hepatobiliary clearances were adjusted by empirical scaling factors (Varma et al., 2014) or parameters were fitted from in vivo intravenous concentration-time profiles using a physiologically based pharmacokinetic (PBPK) model (Jones et al., 2012), the distribution of drugs is altered as low ERdrugs $(\mathrm{ER}<0.2)$ tended to have $\mathrm{RDS}_{\text {all }}$, whereas mid- and high-ER drugs $(\mathrm{ER}>0.2)$ were more likely to have $\operatorname{RDS}_{\text {uptake }}$ (Fig. 6B). This analysis of the published in vitro hepatobiliary clearances provides insight that drugs with $\operatorname{RDS}_{\text {uptake }}$ exist within the moderate RDS framework space, meaning that in general their $\mathrm{CL}_{\text {met }}+$ bile $/ \mathrm{CL}_{\mathrm{ef}}^{\mathrm{s}}$ ratio is $<4$, and they are quite susceptible to the RDS switch (Supplementary Table 1). It further elucidates that current in vitro quantification techniques may underestimate $\mathrm{CL}_{\mathrm{in}}^{\mathrm{s}}$, which can lead to erroneous labeling of the RDS and thus incorrect DDI liability predictions (Fig. 7; Supplementary Fig. 3).
To illustrate more fully the applicability of the RDS framework, predicted DDI liabilities using the RDS framework were compared with in vivo DDI examples. As indicated in Table 1, when empirical scaling factors are used during the IVIVE process or hepatobiliary clearances were estimated from in vivo via PBPK, atorvastatin and repaglinide have $\mathrm{RDS}_{\text {uptake }}$ and $\mathrm{PI}_{\text {met }}+$ bile of $10 \%-51 \%$ and $15 \%-40 \%$, respectively, whereas bosentan has $\mathrm{RDS}_{\text {all }}$. For atorvastatin and repaglinide, the in vitro data predicted that uptake transporters (OATPs) are the primary DDI liability, with the drugs' major metabolic enzymes (CYP3A and CYP2C8, respectively) becoming a potential liability only if the in vivo hepatic metabolic inhibition is greater than the $\mathrm{PI}_{\text {met }}+$ bile. For bosentan, the in vitro data predicted that both OATPs and CYP3A4 are potential DDI liabilities. Clinically, for atorvastatin, coadministration of rifampin (an OATP inhibitor) leads to an AUCR of 12, whereas 33\% inhibition of CYP3A4 due to intravenous itraconazole (as measured using CYP3A4 probe midazolam) did not change atorvastatin systemic AUC, even though inhibition of atorvastatin metabolism was observed via a decrease in the 2-hydroxyatorvastatin concentrations (Maeda et al., 2011). In a similarly conducted experiment, coadministration of rifampin resulted in AUCR of 3.2 and 1.9 for bosentan or repaglinide, respectively, whereas $73 \%$ inhibition of CYP3A4 owing to intravenous itraconazole did not significantly change the systemic AUC of these drugs (Yoshikado et al., 2017). Furthermore, repaglinide coadministered with oral rifampin and trimethoprim (CYP2C8-selective inhibitor) resulted in AUCR 2.6 and 1.8, respectively (Kim et al., 2016). The in vivo DDI liability for OATPs was well predicted for all three victim drugs. The in vivo DDI liability for CYP3A4 was well predicted for atorvastatin. Since a probe was not used to assess the degree of CYP2C8 inhibition, it is difficult to determine whether the significant DDI when repaglinide was coadministered with trimethoprim was because RDS $_{\text {uptake }}$ switched to RDSall or because repaglinide truly has $\mathrm{RDS}_{\text {all }}$. The in vitro metrics, as well as a whole-body PBPK DDI model, suggests that repaglinide has RDS $_{\text {uptake }}$ (Varma et al., 2013); thus, the repaglinide-trimethoprim DDI is likely due to the RDS switch. Lastly, since bosentan was predicted to have $\mathrm{RDS}_{\text {all }}$, a DDI was expected to result from CYP3A4 inhibition, but none was observed. It should be noted that the metabolic DDI liability prediction is assuming one main 


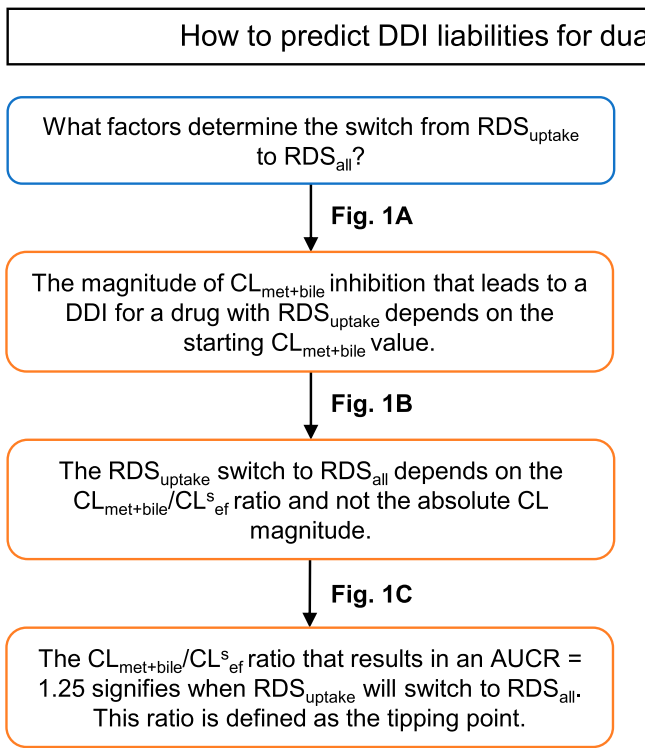

How to predict DDI liabilities for dual enzyme/transporter substrates?

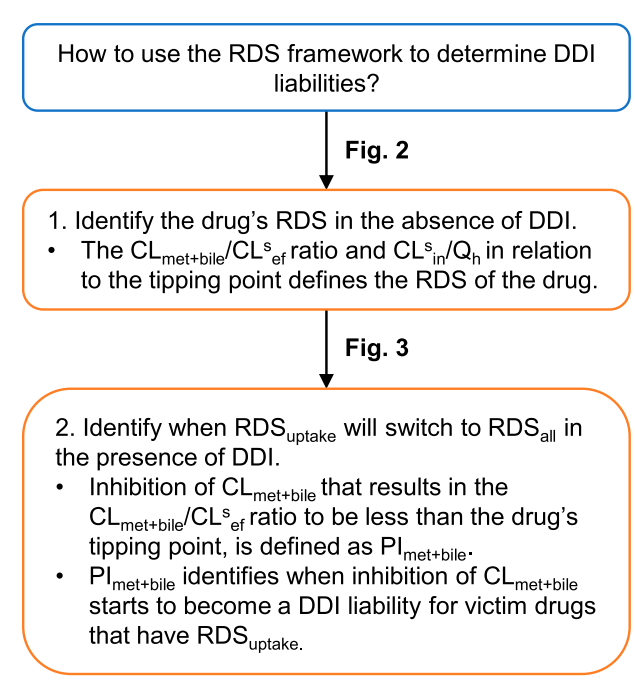

Fig. 4. Summary of the purpose and conclusions for the simulations used to establish the RDS framework. drug-metabolizing enzyme and no significant biliary efflux (e.g., $\mathrm{CL}_{\text {met }}+$ bile $=\mathrm{CL}_{\mathrm{CYP3A} 4}$ for atorvastatin and bosentan). This assumption predicts the highest DDI risk owing to inhibition of $\mathrm{CL}_{\text {met }}+$ bile and has a higher chance of predicting false-positive DDI results.

In the published in vitro data sets, discrepancies in the in vitro quantified values, particularly for $\mathrm{CL}_{\mathrm{in}}^{\mathrm{s}}$, can be observed (Supplementary Table 1; Table 1). For example, in one report, the authors used empirical scaling factors for active sinusoidal uptake clearance to match hepatic clearance with clinically observed data that ranged from 1.1 to 101.8 with a geometric mean of 10.6 (Varma et al., 2014); however, the scaling factor used severely impacted the labeling of the RDS (e.g., fluvastatin, glyburide, pravastatin) or impacted the predicted $\mathrm{PI}_{\mathrm{met}}+$ bile of drugs (e.g., atorvastatin, rosuvastatin, fluvastatin, repaglinide) (Supplementary Table 1). Assumptions regarding $\mathrm{CL}_{\mathrm{ef}}^{\mathrm{s}}$ also caused discrepancies. In all reports, $\mathrm{CL}_{\mathrm{ef}}^{\mathrm{s}}$ was assumed to be equal to passive diffusion across the sinusoidal membrane, except in one report in which $\mathrm{CL}_{\mathrm{ef}}^{\mathrm{s}}$ was backcalculated from total sandwich cultured human hepatocytes $\mathrm{CL}_{\text {int }}$ (Camenisch and Umehara, 2012). The assumptions surrounding $\mathrm{CL}_{\mathrm{ef}}^{\mathrm{s}}$ impacted the $\mathrm{CL}_{\text {met }+ \text { bile }} / \mathrm{CL}_{\mathrm{ef}}^{\mathrm{s}}$ ratio, which either changed how the RDS was labeled or the magnitude of the $\mathrm{PI}_{\mathrm{met}}+$ bile (e.g., aliskerin, ciprofloxacin, digoxin) (Supplementary Table 1). All in all, mispredictions of any of the hepatobiliary clearances impact the RDS

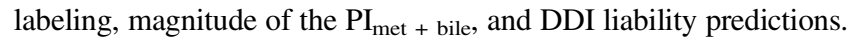

Errors from in vitro quantification of hepatobiliary clearances can propagate when establishing the RDS and the predicted DDI liabilities. Underprediction of both $\mathrm{CL}_{\text {in }}^{\mathrm{s}}$ and $\mathrm{CL}_{\text {met }}$ bile may erroneously label a drug with $\mathrm{RDS}_{\text {all }}$ when it is truly $\mathrm{RDS}_{\text {uptake }}$ (Fig. 7). $\mathrm{CL}_{\text {met }}+$ bile is the more sensitive parameter for determining the RDS because underpredictions of $\mathrm{CL}_{\text {in }}^{\mathrm{s}}$ may mislabel the RDS only for drugs with $\mathrm{CL}_{\mathrm{met}}+$ bile $/ \mathrm{CL}_{\mathrm{ef}}^{\mathrm{s}}$ ratio $<4$ (Supplementary Fig. 4). For such drugs, even moderate (e.g., 2- to 5-fold) underpredictions of either clearance pathway will lead to RDS mislabeling (Supplementary Fig. 4). Furthermore, underpredictions of both $\mathrm{CL}_{\text {in }}^{\mathrm{s}}$ and $\mathrm{CL}_{\text {met }}+$ bile leads to underprediction of $\mathrm{PI}_{\text {met }}+$ bile, resulting in

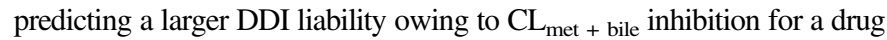
with $\operatorname{RDS}_{\text {uptake }}$ (Fig. 7; Supplementary Fig. 4). Whereas underpredictions of hepatobiliary clearances will result in conservative DDI decisions, they also increase the chances of negative DDI studies.

\section{Discussion}

We built a theoretical RDS framework and identified important considerations when predicting DDI liabilities for dual transporter-enzyme

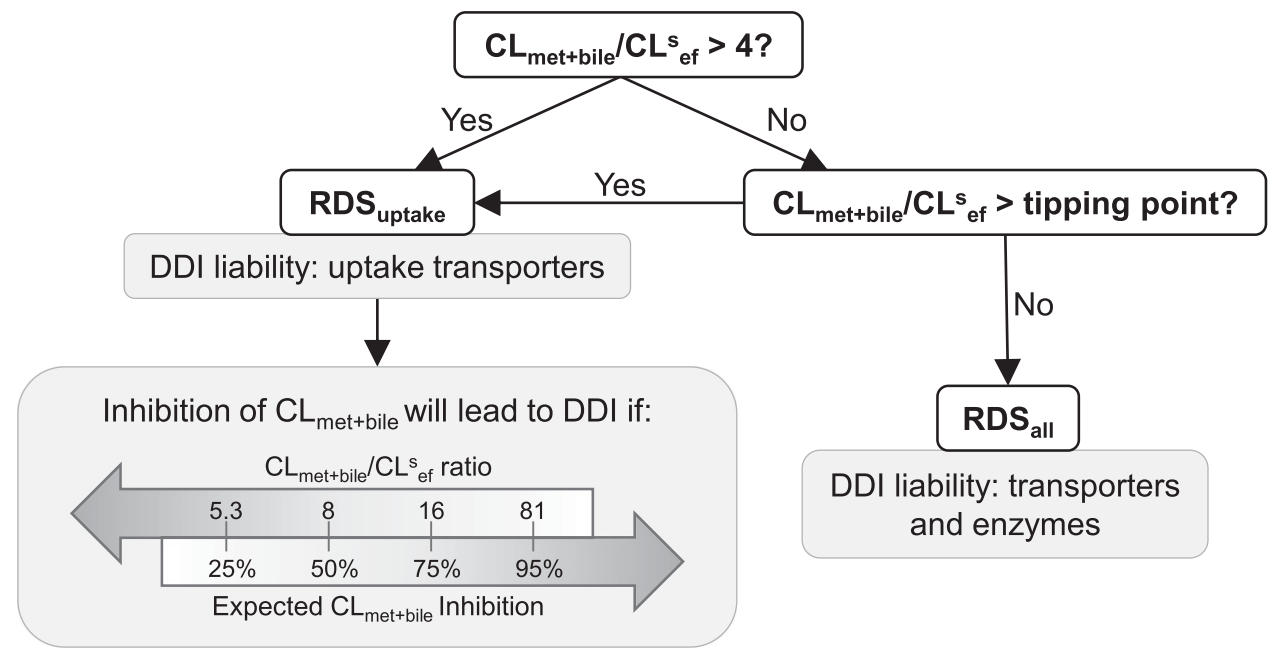

Fig. 5. Applying the RDS framework to identify DDI liabilities for dual transporterenzyme substrate drugs. If $\mathrm{CL}_{\mathrm{met}}+$ bile $_{\mathrm{CL}} / \mathrm{LL}_{\mathrm{ef}}^{\mathrm{s}}>$ 4 , then the drug will have $\operatorname{RDS}_{\text {uptake, }}$ irrespective of the magnitude of $\mathrm{CL}_{\text {in }}^{\mathrm{s}}$. For drugs with RDS $_{\text {uptake, }}$ DDIs due to inhibition of $\mathrm{CL}_{\text {met }}+$ bile can become significant, depending on the drug's $\mathrm{CL}_{\text {met }}+$ bile $/ \mathrm{CL}_{\mathrm{ef}}^{\mathrm{s}}$ ratio and the expected inhibition of $\mathrm{CL}_{\text {met }}+$ bile. For example, $50 \%$ inhibition of $\mathrm{CL}_{\text {met }}+$ bile may result in a significant DDI for a drug with RDS $_{\text {uptake }}$ and $\mathrm{CL}_{\text {met }+ \text { bile }} / \mathrm{CL}_{\mathrm{ef}}^{\mathrm{s}}$ ratio $<8$ but no DDI will be observed if the drug has $\mathrm{CL}_{\text {met }}+$ bile $/ \mathrm{CL}_{\mathrm{ef}}^{\mathrm{s}}$ ratio $>8$. The DDI liability owing to inhibition of $\mathrm{CL}_{\text {met }}+$ bile increases as the $\mathrm{CL}_{\text {met }}+$ bile $/ \mathrm{CL}_{\mathrm{ef}}^{\mathrm{s}}$ ratio decrease and the expected $\mathrm{CL}_{\text {met }}+$ bile inhibition increases. 
A

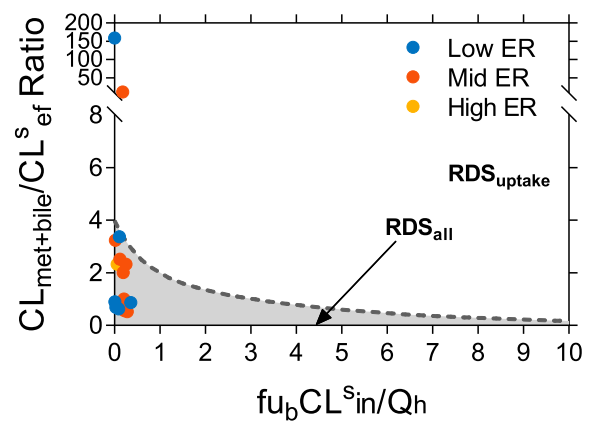

B

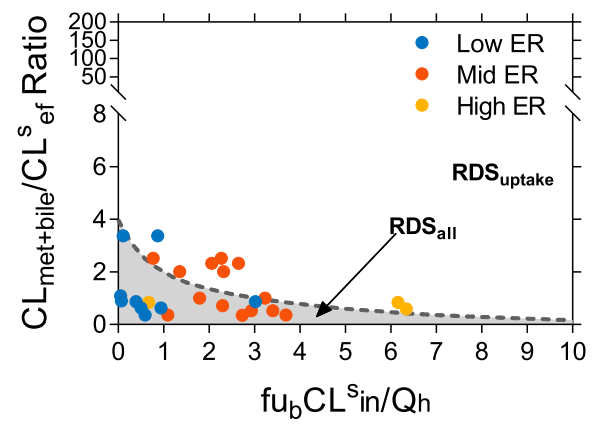

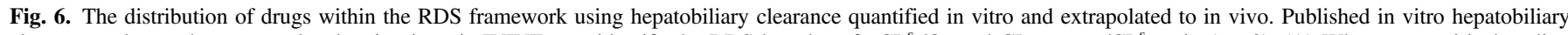

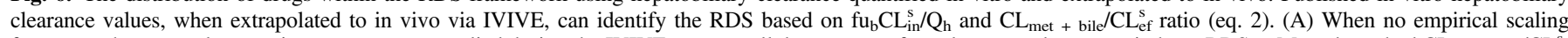

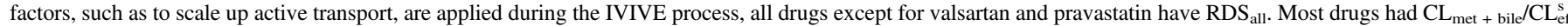

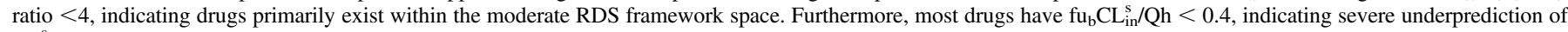

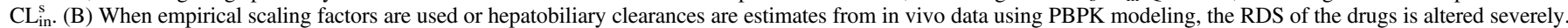

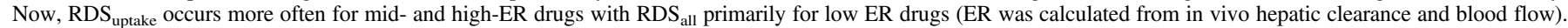

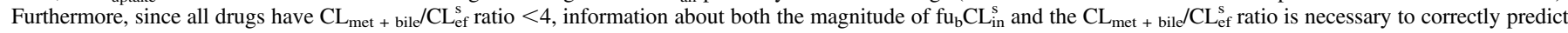

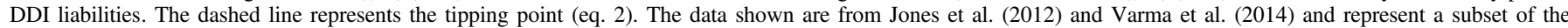
complete data set presented in Supplementary Table 1.

substrate drugs. First, inhibition of $\mathrm{CL}_{\text {met }}+$ bile can cause the RDS of a victim drug to switch from $\mathrm{RDS}_{\text {uptake }}$ to $\mathrm{RDS}_{\text {all }}$ and hence result in an unexpected systemic DDI. Two metrics have been developed to identify when the RDS switch occurs: the tipping point, defined as the $\mathrm{CL}_{\text {met }}+$ bile $/ \mathrm{CL}_{\mathrm{ef}}^{\mathrm{s}}$ ratio at which $\mathrm{RDS}_{\text {uptake }}$ will switch to $\mathrm{RDS}_{\text {all }}$, and the $\mathrm{PI}_{\text {met }+ \text { bile, }}$, defined as the percent inhibition of $\mathrm{CL}_{\text {met }}+$ bile at which a significant AUC change (AUCR >1.25) for a drug with $\operatorname{RDS}_{\text {uptake }}$ will start to be observed. The tipping point depends on the drug's $\mathrm{CL}_{\mathrm{met}}+{ }_{\text {bile }} / \mathrm{CL}_{\mathrm{ef}}^{\mathrm{s}}$ ratio and on the magnitude of $\mathrm{CL}_{\mathrm{in}}^{\mathrm{s}}$. The former but not the latter condition is relevant when victim drugs are administered orally. Second, we showed that the $\mathrm{CL}_{\mathrm{met}}+$ bile $/ \mathrm{CL}_{\mathrm{ef}}^{\mathrm{s}}$ ratio must be $>4$ for any drug to have $\mathrm{RDS}_{\text {uptake. Third, we applied }}$ the RDS framework to in vitro-quantified hepatobiliary clearances and observed that most drugs have $\mathrm{CL}_{\text {met + bile }} / \mathrm{CL}_{\mathrm{ef}}^{\mathrm{s}}$ ratio $<4$; hence, in practice, the magnitude of $\mathrm{CL}_{\text {in }}^{\mathrm{s}}$ must be considered when establishing the RDS.

Our theoretical analysis demonstrates that the $\mathrm{CL}_{\text {met }+ \text { bile }} / \mathrm{CL}_{\mathrm{ef}}^{\mathrm{s}}$ ratio, and not the absolute magnitudes of the clearances, determines the RDS in the hepatic clearance of a drug. Previous publications allude to this relationship. The authors of the ECCCS observed through experimental data that when $\mathrm{CL}_{\text {met }}+$ bile is $2 \times \mathrm{CL}_{\mathrm{ef}}^{\mathrm{s}}$, drugs that have $\mathrm{RDS}_{\text {uptake }}$ can be separated from those that do not (Riede et al., 2016). Furthermore, the $\beta$ value $\left[\beta=\mathrm{CL}_{\text {met }}+\right.$ bile $/\left(\mathrm{CL}_{\text {met }}+\right.$ bile $\left.\left.+\mathrm{CL}_{\mathrm{ef}}^{\mathrm{s}}\right)\right]$ introduced by Yoshikado et al. (2016) can be used to differentiate the RDS, such as when $\beta$ approaches unity (i.e., $\mathrm{CL}_{\text {met + bile }}>>\mathrm{CL}_{\mathrm{ef}}^{\mathrm{S}}$ ), a drug has $\mathrm{RDS}_{\text {uptake. }}$ Our analyses corroborate and expand upon these results to provide a quantitative definition of the demarcation point between $\operatorname{RDS}_{\text {uptake }}$ and $\operatorname{RDS}_{\text {all }}$ (i.e., the tipping point) and illustrate that the magnitude of $\mathrm{CL}_{\mathrm{in}}^{\mathrm{s}}$, in addition to the $\mathrm{CL}_{\mathrm{met}}+$ bile $/ \mathrm{CL}_{\mathrm{ef}}^{\mathrm{s}}$ ratio, is an important factor in determining the RDS of a drug. That is, as a drug's $\mathrm{CL}_{\text {in }}^{\mathrm{s}}$ value increases, the drug is more likely to have $\mathrm{RDS}_{\text {uptake }}$ and to become resistant to the RDS $_{\text {uptake }}$ switch to $\operatorname{RDS}_{\text {all }}$.

We found good agreement for atorvastatin in vivo to predict DDI liabilities (Table 1). For bosentan, overprediction of expected DDI owing to inhibition of $\mathrm{CL}_{\text {met }}+$ bile may be due to errors in the quantification of the hepatobiliary clearances. Indeed, a study in cynomolgus monkeys, in which bosentan plasma and liver drug concentrations were quantified, found that the in vitro scaled $\mathrm{CL}_{\mathrm{in}}^{\mathrm{s}}$ and $\mathrm{CL}_{\text {met }}$ were 28- and 13-fold underpredicted, whereas $\mathrm{CL}_{\mathrm{ef}}^{\mathrm{s}}$ (assumed equal to passive diffusion) was overpredicted by 2 -fold compared with the in vivo-fitted values (Morse et al., 2017). Combining the in vitro metrics that identify $\operatorname{RDS}_{\text {uptake }}$ for repaglinide with in vivo repaglinide DDIs, it appears that CYP2C8 but not CYP3A4 inhibition may lead to $\mathrm{RDS}_{\text {uptake }}$ switch to $\mathrm{RDS}_{\text {all }}$. Indeed, inhibition of repaglinide with gemfibrozil (CYP2C8 and OATP1B1 inhibitor) led to an 8-fold increase in systemic AUC; coadministration of itraconazole or cyclosporine (OATP1B1 and CYP3A4 inhibitor) led to much more modest 1.4- and 2.4-fold increases in systemic AUC (Niemi et al., 2003; Kajosaari et al., 2005).
A

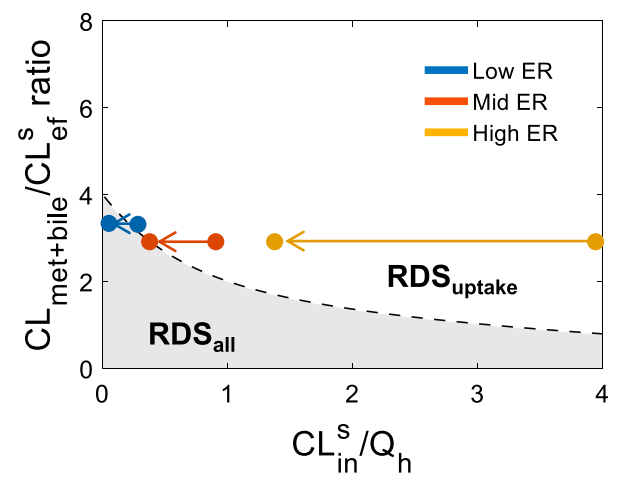

B

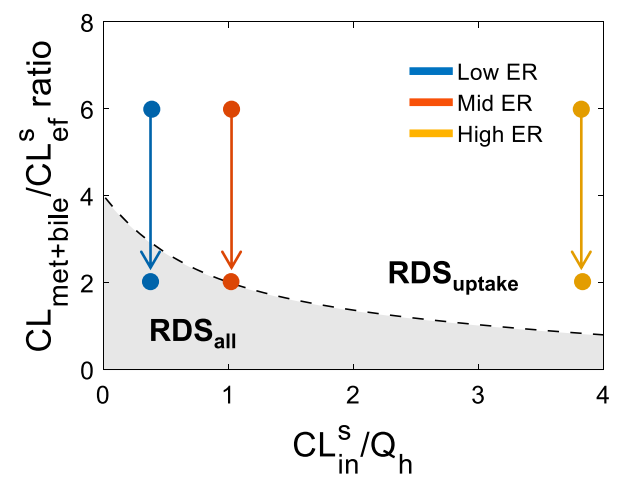

Fig. 7. The impact of underpredictions of hepatobiliary clearance on DDI liability predictions. A representative 3 -fold underprediction of either (A) $C L_{\text {in }}^{\mathrm{s}}$ or (B) $C L_{\text {met }}+$ bile can lead to erroneous labeling of the RDS for low-, mid-, and high-ER drugs (shown by the filled circles crossing from the nonshaded to shaded area (i.e., RDS $_{\text {uptake }}$ switches to RDS $_{\text {all }}$ ). Mislabeling the RDS impacts the expected DDI risk from transporters versus enzymes. Furthermore, underpredictions of either $\mathrm{CL}_{\text {in }}^{\mathrm{s}}$ or $\mathrm{CL}_{\text {met }}+$ bile leads to identifying both transporters and enzymes as DDI liabilities when truly only uptake transporters are the true DDI liability. Please refer to Supplementary Fig. 4 for more detailed simulations. 
TABLE 1

Comparison of predicted drug-drug interaction (DDI) liabilities from in vitro data to in vivo clinical studies

Hepatobiliary clearances, after in vitro to in vivo extrapolation (IVIVE), can be used to identify the rate-determining step (RDS) of a drug, such as if the $\mathrm{CL}_{\text {met }}+$ bile $/ \mathrm{CL}_{\mathrm{ef}}^{\mathrm{s}}$ ratio is $>$ or $<$ than the

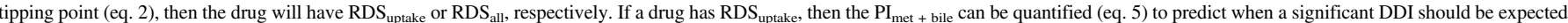
owing to inhibition of metabolic/biliary efflux clearance. An expanded analysis is shown in Supplementary Table 1.

\begin{tabular}{|c|c|c|c|c|c|c|c|c|c|c|c|}
\hline \multirow{2}{*}{ Drug } & \multicolumn{4}{|c|}{ Hepatobiliary Clearance $(\mathrm{ml} / \mathrm{min}$ per $\mathrm{kg})$} & \multirow{2}{*}{$\mathrm{fu}_{\mathrm{b}} \mathrm{CL}_{\mathrm{in}}^{\mathrm{s}} / \mathrm{Qh}^{a}$} & \multirow{2}{*}{$\mathrm{CL}_{\text {met }}+$ bile $/ \mathrm{CL}_{\mathrm{ef}}^{\mathrm{s}}$} & \multirow{2}{*}{ Tipping Point } & \multirow{2}{*}{$\mathrm{PI}_{\mathrm{met}}+$ bile } & \multirow{2}{*}{ RDS In Vitro } & \multirow{2}{*}{ RDS In Vivo } & \multirow{2}{*}{ Reference } \\
\hline & $\mathrm{CL}_{\text {in }}^{\mathrm{s}}$ & $C L_{\text {ef }}^{\mathrm{s}}$ & $\mathrm{CL}_{\text {met }}$ & $\mathrm{CL}_{\text {bile }}$ & & & & & & & \\
\hline \multirow[t]{5}{*}{ Atorvastatin } & $61^{b}$ & 24.9 & 58.3 & 4.3 & 0.12 & 2.52 & 3.59 & - & All & Uptake $^{c}$ & Varma et al. (2014) \\
\hline & $1194^{d}$ & 24.9 & 58.3 & 4.3 & 2.27 & 2.52 & 1.22 & $>51 \%$ & Uptake & & Camenisch and Umehara (2012) \\
\hline & $405^{e}$ & 24.9 & 58.3 & 4.3 & 0.77 & 2.52 & 2.26 & $>10 \%$ & Uptake & & Kunze et al. (2015) \\
\hline & $198^{b}$ & 359 & 64.6 & 11.8 & 0.80 & 0.21 & 2.22 & - & All & & Maeda et al. (2011) \\
\hline & $198^{b}$ & 57.7 & 64.6 & 11.8 & 0.80 & 1.32 & 2.22 & - & All & & \\
\hline \multirow[t]{5}{*}{ Bosentan } & $132^{b}$ & 28.9 & 19.5 & 5.8 & 0.36 & 0.87 & 2.95 & - & All & Uptake $^{c}$ & Varma et al. (2014) \\
\hline & $142^{d}$ & 28.9 & 19.5 & 5.8 & 0.38 & 0.87 & 2.90 & - & All & & Jones et al. (2012) \\
\hline & $1117^{e}$ & 28.9 & 19.5 & 5.8 & 3.02 & 0.87 & 0.99 & - & All & & Yoshikado et al. (2017) \\
\hline & $35^{b}$ & 12.1 & - & $39^{f}$ & 0.02 & 3.24 & 3.93 & - & All & & \\
\hline & $2035^{g}$ & 14 & - & $5.0^{f}$ & 1.09 & 0.36 & 1.91 & - & All & & \\
\hline \multirow[t]{5}{*}{ Repaglinide } & $166^{b}$ & 63.6 & 128 & 0.3 & 0.19 & 2.01 & 3.35 & - & All & Uptake $^{c}$ all $^{h}$ & Varma et al. (2014) \\
\hline & $1983^{d}$ & 63.6 & 128 & 0.3 & 2.32 & 2.01 & 1.21 & $>40 \%$ & Uptake & & Jones et al. (2012) \\
\hline & $1151^{e}$ & 63.6 & 128 & 0.3 & 1.35 & 2.01 & 1.71 & $>15 \%$ & Uptake & & Yoshikado et al. (2017) \\
\hline & $299^{b}$ & 223 & 125 & 0.0 & 0.22 & 0.56 & 3.27 & - & All & & \\
\hline & $3671^{g}$ & 352 & 125 & 0.0 & 2.73 & 0.35 & 1.07 & - & All & & \\
\hline
\end{tabular}

${ }^{a} \mathrm{The}_{\mathrm{fu}}$ and $\mathrm{Q}_{\mathrm{h}}$ values as noted in each reference were used for analysis; note that fu $\mathrm{b}_{\mathrm{b}}$ may vary for the same drug across different references.

${ }^{b}$ In vitro quantified + IVIVE.

${ }^{c}$ RDS $_{\text {uptake }}$ was established in vivo for atorvastatin and bosentan since there was no significant AUC change to victim drugs when coadministered with intravenous itraconazole (CYP3A inhibitor)

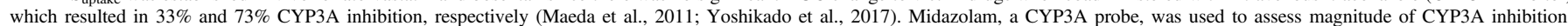

$\mathrm{RDS}_{\text {uptake }}$ was established for repaglinide via whole-body physiologically based pharmacokinetic (PBPK) modeling of complex transporter- and enzyme-mediated DDIs (Varma et al., 2013).

${ }^{d}$ In vitro quantified + IVIVE + empirical scaling factor for active uptake transport (individual scaling factor).

${ }^{e}$ In vitro quantified + IVIVE + empirical scaling factor for active uptake transport (geometric mean scaling factor).

${ }^{f}$ Composite $\mathrm{CL}_{\text {met }}+$ bile.

${ }^{g}$ Fitted parameters from in vivo using PBPK model.

${ }^{h} \mathrm{RDS}_{\text {all }}$ was established in vivo for repaglinide even though there was no change to systemic AUC by intravenous itraconazole because CYP2C8 is the major hepatic drug-metabolizing enzyme (Yoshikado et al., 2017). In a different study, oral trimethoprim, a selective CYP2C8 inhibitor, increased repaglinide AUC by 1.8-fold (Kim et al., 2016).

The DDI liabilities discussed so far are relevant for systemic drug exposure but not necessarily for hepatic drug exposure, and thus efficacy/toxicity, if the site of action is in the liver. For example, the low-density lipoprotein cholesterol-lowering effect mediated by atorvastatin does not change for subjects with OATP1B1 polymorphism c.521T $>C$, even though there is a significant increase in atorvastatin systemic AUC (Maeda, 2015). This is because if the liver is the main eliminating organ, changes to sinusoidal uptake alter the hepatic concentration-time profile but not the hepatic AUC; however, a systemic increase of atorvastatin may lead to off-target toxicity, such as muscle myopathy. We refer the readers to our previous publication (PatileaVrana and Unadkat, 2016), which describes simulations that demonstrate the impact of inhibition of uptake or metabolism on both systemic and hepatic AUC when the liver is and is not the main eliminating organ.

The contrast between in vitro quantified $\mathrm{CL}_{\text {in }}^{\mathrm{s}}$ with and without empirical scaling factors in Fig. 6 demonstrates that IVIVE of accurate transportermediated clearance remains challenging (Chu et al., 2013; Feng et al., 2014). The system used for in vitro quantification may be crucial since $C L_{\text {in }}^{S}$ for statins quantified in sandwich cultured human hepatocytes appeared to be lower in magnitude than when quantified in suspended hepatocytes (Supplementary Table 1; Table 1). This may be mediated by significant intracellular localization of plasma membrane transporters (Kumar et al., 2017) or high interindividual variability when using individual donors (Vildhede et al., 2014). These reasons may also cause underpredictions of $\mathrm{CL}_{\text {in }}^{\mathrm{s}}$ or $\mathrm{CL}_{\text {bile. }}$ For transporter IVIVE, we have previously recommended using a bottom-up proteomic approach and adjusting for in vitro activity via IVIVE transporter expression-based scaling factors (Prasad and Unadkat, 2014). We have recently demonstrated the successful prediction of hepatobiliary clearance of rosuvastatin in rats using the aforementioned approach (Ishida et al., 2018).

Special emphasis needs to be given to quantifying $\mathrm{CL}_{\mathrm{ef}}^{\mathrm{s}}$ along with $\mathrm{CL}_{\text {met }}+$ bile since the $\mathrm{CL}_{\text {met }}+$ bile $/ C L_{\text {ef }}^{\mathrm{s}}$ ratio is one of the anchor points when establishing the RDS. Because $\mathrm{CL}_{\mathrm{ef}}^{\mathrm{s}}$ is a difficult parameter to quantify in vitro, it is typically assumed to be equal to passive diffusion across the sinusoidal membrane; however, there are examples of active sinusoidal efflux transport, such as MRP3 efflux of rosuvastatin (Pfeifer et al., 2013). Active sinusoidal efflux would increase the magnitude of $\mathrm{CL}_{\mathrm{ef}}^{\mathrm{s}}$ and decrease the $\mathrm{CL}_{\text {met }}+$ bile $/ \mathrm{CL}_{\mathrm{ef}}^{\mathrm{s}}$ ratio, making a drug more likely to have $\mathrm{RDS}_{\mathrm{all}}$. One approach to measuring $\mathrm{CL}_{\mathrm{ef}}^{\mathrm{s}}$ is to use an integrative temporal modeling approach in sandwich cultured hepatocytes (Pfeifer et al., 2013; Ishida et al., 2018).

Errors in the quantification of $\mathrm{CL}_{\text {in }}^{\mathrm{s}}$ and/or the $\mathrm{CL}_{\text {met }}+$ bile $/ \mathrm{CL}_{\mathrm{ef}}^{\mathrm{s}}$ ratio can impact DDI liability predictions. For example, patients with OATP1B1 polymorphism c.521T $>\mathrm{C}$ have about a 2-fold greater atorvastatin AUC compared with the wild-type allele (Maeda, 2015). Because of the lower $\mathrm{CL}_{\mathrm{in}}^{\mathrm{s}}$, and therefore greater susceptibility to the $\mathrm{RDS}_{\text {uptake }}$ to RDS $\mathrm{all}_{\text {all }}$ switch, patients with OATP1B1 polymorphism may experience a DDI attributable to inhibition of CYP3A, whereas patients with the wild-type allele may not. The same trend would be true for patients with polymorphic enzymes that result in lower $\mathrm{CL}_{\text {met }}+$ bile and thus lower $\mathrm{CL}_{\text {met }}+$ bile $/ \mathrm{CL}_{\mathrm{ef}}^{\mathrm{s}}$ ratios. Polypharmacy use can also impact DDI liability predictions. For example, highly active antiretroviral therapy typically includes potent CYP3A4 and moderate OATP inhibitor ritonavir, among other drugs, which can impact the $\mathrm{CL}_{\text {met }}+$ biled $\mathrm{CL}_{\mathrm{ef}}^{\mathrm{s}}$ ratio more severely than if only one drug is administered. Indeed, the systemic AUC of atorvastatin increased by 3.9- and 9.4-fold when coadministered with saquinavir/ritonavir and tipranavir/ritonavir, respectively (Fichtenbaum et al., 2002; Pham et al., 2009). Lastly, the saturation of enzymes, leading to a lower $\mathrm{CL}_{\text {met }}$ with increased dose, may lower the $\mathrm{CL}_{\text {met }}+$ bile $/ \mathrm{CL}_{\text {ef }}^{\mathrm{s}}$ ratio and cause DDIs owing to the $\mathrm{RDS}_{\text {uptake }}$ switch to $\mathrm{RDS}_{\text {all }}$.

If a victim drug has $\mathrm{RDS}_{\text {all }}$, but it has been mislabeled as $\mathrm{RDS}_{\text {uptake, }}$ then the DDI liability owing to inhibition of both transporter and metabolic activity could be underestimated. Considering potential DDI risks, it would be most conservative to assume a drug has $\operatorname{RDS}_{\text {all }}$; however, making such an assumption would lead to an increase in 
negative DDI studies, particularly when conducting metabolic or biliary

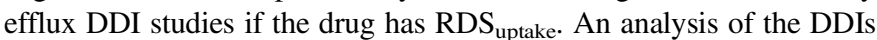
performed for a cohort of NMEs in 2013 showed a modest return on investment because $57 \%(n=141)$ of all in vivo DDIs were negative (Lesko and Lagishetty, 2016). Given the high prevalence of negative DDIs, it may be more appropriate to make mechanistic-based rather than conservative decisions regarding DDI liabilities.

The RDS framework presented here should be used as a guide for identifying the DDI liabilities, whereas PBPK models should be used to predict the direction and magnitude of complex transporter-enzyme DDIs. Several examples of such models (e.g., repaglinide, simvastatin, rosuvastatin) exist that predict complex interactions resulting from chemical inhibition or genetic polymorphism (Varma et al., 2013; Rose et al., 2014; Tsamandouras et al., 2015). Even with PBPK models, there are limitations. For example, when a drug has $\mathrm{RDS}_{\text {uptake, }}$ the $\mathrm{CL}_{\mathrm{met}}+$ bile is unidentifiable from plasma concentrations data since only $\mathrm{CL}_{\text {in }}^{\mathrm{s}}$ plays a significant role in determining hepatic clearance. Focusing on capturing the correct $\mathrm{CL}_{\text {met }+ \text { bile }}$ magnitude, and not the $\mathrm{CL}_{\text {met }+ \text { bile }} / \mathrm{CL}_{\mathrm{ef}}^{\mathrm{s}}$ ratio, can be misleading and will impact PBPK predictions. For instance, in an atorvastatin PBPK model, when cyclosporine CYP3A4 $\mathrm{K}_{\mathrm{i}}$ was modulated 100-fold, a maximum 1.6-fold AUCR was achieved (Duan et al., 2017). Although the tendency is to run sensitivity analysis on the active components (transport and metabolism), a sensitivity analysis on $\mathrm{CL}_{\mathrm{ef}}^{\mathrm{s}}$ value (in the model, it was assumed to be equal to passive diffusion) should also be run as, for the specific example provided, it would likely have revealed a larger impact of cyclosporine on atorvastatin systemic AUC. Such an analysis may be helpful in consolidating in vitro $K_{\mathrm{i}}$ data with observed in vivo DDI data.

In summary, we introduced a theoretical RDS framework to predict more completely DDI liabilities for drugs that are dual transporterenzyme substrates. We provide useful insights, such as the following: 1) the $\mathrm{RDS}_{\text {uptake }}$ switch to $\mathrm{RDS}_{\text {all }}$ depends on the ratio of $\mathrm{CL}_{\mathrm{met}}+$ bile $/ \mathrm{CL}_{\mathrm{ef}}^{\mathrm{s}}$ and the magnitude of $\mathrm{CL}_{\text {in }}^{\mathrm{s}}$; 2) $\mathrm{CL}_{\text {met }}+{ }_{\text {bile }} / \mathrm{CL}_{\mathrm{ef}}^{\mathrm{s}}$ ratio $>4$ ensures $\mathrm{RDS}_{\text {uptake }}$ independent of $\mathrm{CL}_{\text {in }}^{\mathrm{s}}$ magnitude or administration route; 3) there are existing drugs within a moderate space within the RDS framework that are susceptible to the $\mathrm{RDS}_{\text {uptake }}$ switch to $\mathrm{RDS}_{\text {all }}$. Whereas these insights were obtained from the hepatic ECM, they can be equally applied to other organs, such as the kidneys, in which vectorial (basal-to-apical) transport of drugs is possible.

\section{Acknowledgments}

We thank Bhagwat Prasad and Neha Maharao for insightful and constructive comments and suggestions, as well as the anonymous reviewers, who gave excellent feedback to improve the clarity and significance of this work and whose suggestions prompted us to derive the explicit solution for the tipping point.

\section{Authorship Contributions}

Participated in research design: Patilea-Vrana, Unadkat.

Conducted experiments: Patilea-Vrana.

Contributed new reagents or analytical tool: Patilea-Vrana.

Performed data analysis: Patilea-Vrana.

Wrote or contributed to the writing of the manuscript: Patilea-Vrana, Unadkat.

\section{References}

Backman JT, Kyrklund C, Neuvonen M, and Neuvonen PJ (2002) Gemfibrozil greatly increases plasma concentrations of cerivastatin. Clin Pharmacol Ther 72:685-691.

Camenisch G and Umehara K (2012) Predicting human hepatic clearance from in vitro drug metabolism and transport data: a scientific and pharmaceutical perspective for assessing drugdrug interactions. Biopharm Drug Dispos 33:179-194.

Chu X, Korzekwa K, Elsby R, Fenner K, Galetin A, Lai Y, Matsson P, Moss A, Nagar S, Rosania GR, et al.; International Transporter Consortium (2013) Intracellular drug concentrations and transporters: measurement, modeling, and implications for the liver. Clin Pharmacol Ther 94: 126-141.
Duan P, Zhao P, and Zhang L (2017) Physiologically based pharmacokinetic (PBPK) modeling of pitavastatin and atorvastatin to predict drug-drug interactions (DDIs). Eur J Drug Metab Pharmacokinet 42:689-705.

Endres CJ, Endres MG, and Unadkat JD (2009) Interplay of drug metabolism and transport: a real phenomenon or an artifact of the site of measurement? Mol Pharm 6:1756-1765.

Feng B, Varma MV, Costales C, Zhang H, and Tremaine L (2014) In vitro and in vivo approaches to characterize transporter-mediated disposition in drug discovery. Expert Opin Drug Discov 9:873-890.

Fichtenbaum CJ, Gerber JG, Rosenkranz SL, Segal Y, Aberg JA, Blaschke T, Alston B, Fang F, Kosel B, and Aweeka F; NIAID AIDS Clinical Trials Group (2002) Pharmacokinetic interactions between protease inhibitors and statins in HIV seronegative volunteers: ACTG Study A5047. AIDS 16:569-577.

Giacomini KM, Huang SM, Tweedie DJ, Benet LZ, Brouwer KL, Chu X, Dahlin A, Evers R, Fischer V, Hillgren KM, et al.; International Transporter Consortium (2010) Membrane transporters in drug development. Nat Rev Drug Discov 9:215-236.

Hillgren KM, Keppler D, Zur AA, Giacomini KM, Stieger B, Cass CE, and Zhang L; International Transporter Consortium (2013) Emerging transporters of clinical importance: an update from the International Transporter Consortium. Clin Pharmacol Ther 94:52-63.

Ishida K, Ullah M, Toth B, Juhasz V, and Unadkat JD (2018) Successful prediction of in vivo hepatobiliary clearances and hepatic concentrations of rosuvastatin using sandwich-cultured rat hepatocytes, transporter-expressing cell lines, and quantitative proteomics. Drug Metab Dispos 46:66-74.

Jones HM, Barton HA, Lai Y, Bi YA, Kimoto E, Kempshall S, Tate SC, El-Kattan A, Houston JB, Galetin A, et al. (2012) Mechanistic pharmacokinetic modeling for the prediction of transportermediated disposition in humans from sandwich culture human hepatocyte data. Drug Metab Dispos 40:1007-1017.

Kajosaari LI, Niemi M, Neuvonen M, Laitila J, Neuvonen PJ, and Backman JT (2005) Cyclosporine markedly raises the plasma concentrations of repaglinide. Clin Pharmacol Ther 78: 388-399.

Kim SJ, Yoshikado T, Ieiri I, Maeda K, Kimura M, Irie S, Kusuhara H, and Sugiyama Y (2016) Clarification of the mechanism of clopidogrel-mediated drug-drug interaction in a clinical cassette small-dose study and its prediction based on in vitro information. Drug Metab Dispos 44: $1622-1632$.

Kumar V, Nguyen TB, Tóth B, Juhasz V, and Unadkat JD (2017) Optimization and application of a biotinylation method for quantification of plasma membrane expression of transporters in cells. AAPS J 19:1377-1386.

Kunze A, Poller B, Huwyler J, and Camenisch G (2015) Application of the extended clearance concept classification system (ECCCS) to predict the victim drug-drug interaction potential of statins. Drug Metab Pers Ther 30:175-188.

Kusuhara H and Sugiyama Y (2009) In vitro-in vivo extrapolation of transporter-mediated clearance in the liver and kidney. Drug Metab Pharmacokinet 24:37-52.

Lesko LJ and Lagishetty CV (2016) Are we getting the best return on investment from clinical drug-drug interaction studies? J Clin Pharmacol 56:555-558.

Li R, Barton HA, and Varma MV (2014) Prediction of pharmacokinetics and drug-drug interactions when hepatic transporters are involved. Clin Pharmacokinet 53:659-678.

Maeda K (2015) Organic anion transporting polypeptide (OATP)1B1 and OATP1B3 as important regulators of the pharmacokinetics of substrate drugs. Biol Pharm Bull 38:155-168.

Maeda K, Ikeda Y, Fujita T, Yoshida K, Azuma Y, Haruyama Y, Yamane N, Kumagai Y, and Sugiyama Y (2011) Identification of the rate-determining process in the hepatic clearance of atorvastatin in a clinical cassette microdosing study. Clin Pharmacol Ther 90:575-581.

Miyauchi S, Sugiyama Y, Sawada Y, Morita K, Iga T, and Hanano M (1987) Kinetics of hepatic transport of 4-methylumbelliferone in rats: analysis by multiple indicator dilution method. $J$ Pharmacokinet Biopharm 15:25-38.

Morse BL, MacGuire JG, Marino AM, Zhao Y, Fox M, Zhang Y, Shen H, Griffith Humphreys W, Marathe P, and Lai Y (2017) Physiologically based pharmacokinetic modeling of transportermediated hepatic clearance and liver partitioning of OATP and OCT substrates in cynomolgus monkeys. AAPS J 19:1878-1889.

Mück W, Mai I, Fritsche L, Ochmann K, Rohde G, Unger S, Johne A, Bauer S, Budde K, Roots I, et al. (1999) Increase in cerivastatin systemic exposure after single and multiple dosing in cyclosporine-treated kidney transplant recipients. Clin Pharmacol Ther 65:251-261.

Niemi M, Backman JT, Neuvonen M, and Neuvonen PJ (2003) Effects of gemfibrozil, itraconazole, and their combination on the pharmacokinetics and pharmacodynamics of repaglinide: potentially hazardous interaction between gemfibrozil and repaglinide. Diabetologia 46:347-351.

Patel M, Taskar KS, and Zamek-Gliszczynski MJ (2016) Importance of hepatic transporters in clinical disposition of drugs and their metabolites. J Clin Pharmacol 56 (Suppl 7):S23-S39.

Patilea-Vrana G and Unadkat JD (2016) Transport vs. metabolism: what determines the pharmacokinetics and pharmacodynamics of drugs? Insights from the extended clearance model. Clin Pharmacol Ther 100:413-418.

Paul SM, Mytelka DS, Dunwiddie CT, Persinger CC, Munos BH, Lindborg SR, and Schacht AL (2010) How to improve R\&D productivity: the pharmaceutical industry's grand challenge. Nat Rev Drug Discov 9:203-214.

Pfeifer ND, Yang K, and Brouwer KL (2013) Hepatic basolateral efflux contributes significantly to rosuvastatin disposition I: characterization of basolateral versus biliary clearance using a novel protocol in sandwich-cultured hepatocytes. J Pharmacol Exp Ther 347:727-736.

Pham PA, la Porte CJ, Lee LS, van Heeswijk R, Sabo JP, Elgadi MM, Piliero PJ, Barditch-Crovo P, Fuchs E, Flexner C, et al. (2009) Differential effects of tipranavir plus ritonavir on atorvastatin or rosuvastatin pharmacokinetics in healthy volunteers. Antimicrob Agents Chemother 53:4385-4392.

Prasad B and Unadkat JD (2014) Optimized approaches for quantification of drug transporters in tissues and cells by MRM proteomics. AAPS $J$ 16:634-648.

Riede J, Poller B, Huwyler J, and Camenisch G (2017) Assessing the risk of drug-induced cholestasis using unbound intrahepatic concentrations. Drug Metab Dispos 45:523-531.

Riede J, Poller B, Umehara K, Huwyler J, and Camenisch G (2016) New IVIVE method for the prediction of total human clearance and relative elimination pathway contributions from in vitro hepatocyte and microsome data. Eur J Pharm Sci 86:96-102.

Rose RH, Neuhoff S, Abduljalil K, Chetty M, Rostami-Hodjegan A, and Jamei M (2014) Application of a physiologically based pharmacokinetic model to predict OATP1B1-related variability in pharmacodynamics of rosuvastatin. CPT Pharmacometrics Syst Pharmacol 3:e124.

Shitara Y, Horie T, and Sugiyama Y (2006) Transporters as a determinant of drug clearance and tissue distribution. Eur J Pharm Sci 27:425-446.

Sirianni GL and Pang KS (1997) Organ clearance concepts: new perspectives on old principles. $J$ Pharmacokinet Biopharm 25:449-470. 
Tsamandouras N, Dickinson G, Guo Y, Hall S, Rostami-Hodjegan A, Galetin A, and Aarons L (2015) Development and application of a mechanistic pharmacokinetic model for simvastatin and its active metabolite simvastatin acid using an integrated population PBPK approach. Pharm Res 32:1864-1883.

Varma MV, Bi YA, Kimoto E, and Lin J (2014) Quantitative prediction of transporter- and enzyme-mediated clinical drug-drug interactions of organic anion-transporting polypeptide 1B1 substrates using a mechanistic net-effect model. J Pharmacol Exp Ther 351:214-223.

Varma MV, Lai Y, Kimoto E, Goosen TC, El-Kattan AF, and Kumar V (2013) Mechanistic modeling to predict the transporter- and enzyme-mediated drug-drug interactions of repaglinide. Pharm Res 30:1188-1199.

Varma MV, Steyn SJ, Allerton C, and El-Kattan AF (2015) Predicting clearance mechanism in drug discovery: extended clearance classification system (ECCS). Pharm Res 32:3785-3802.

Vildhede A, Karlgren M, Svedberg EK, Wisniewski JR, Lai Y, Norén A, and Artursson P (2014) Hepatic uptake of atorvastatin: influence of variability in transporter expression on uptake clearance and drug-drug interactions. Drug Metab Dispos 42:1210-1218.

Yoshikado T, Maeda K, Kusuhara H, Furihata KI, and Sugiyama Y (2017) Quantitative analyses of the influence of parameters governing rate-determining process of hepatic elimination of drugs on the magnitudes of drug-drug interactions via hepatic OATPs and CYP3A using physiologically based pharmacokinetic models. J Pharm Sci 106:2739-2750.

Yoshikado T, Yoshida K, Kotani N, Nakada T, Asaumi R, Toshimoto K, Maeda K, Kusuhara H, and Sugiyama Y (2016) Quantitative analyses of hepatic OATP-mediated interactions between statins and inhibitors using PBPK modeling with a parameter optimization method. Clin Pharmacol Ther 100:513-523.

Yu J, Zhou Z, Owens KH, Ritchie TK, and Ragueneau-Majlessi I (2017) What can Be learned from recent new drug applications? A systematic review of drug interaction data for drugs approved by the US FDA in 2015. Drug Metab Dispos 45:86-108.

Address correspondence to: Dr. Jashvant D. Unadkat, Department of Pharmaceutics, University of Washington, Box 357610, Seattle, WA 98195. E-mail: jash@ uw.edu 